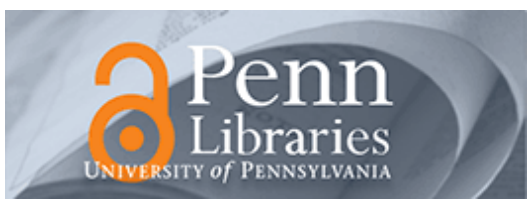

University of Pennsylvania ScholarlyCommons

Wharton Pension Research Council Working

Papers

Wharton Pension Research Council

6-1-2011

\title{
Beyond Age and Sex: Enhancing Annuity Pricing
}

Joelle HY Fong

The Wharton School, University of Pennsylvania, hfong@wharton.upenn.edu

Follow this and additional works at: https://repository.upenn.edu/prc_papers

Part of the Economics Commons

Fong, Joelle HY, "Beyond Age and Sex: Enhancing Annuity Pricing" (2011). Wharton Pension Research Council Working Papers. 169. https://repository.upenn.edu/prc_papers/169

Fong is a doctoral student and S.S. Huebner Foundation Fellow at the Wharton School, University of Pennsylvania. All opinions are solely that of the author who acknowledges research support from the Pension Research Council/Boettner Center at The Wharton School. Without implicating them, I would like to thank Irma Elo, Dean Foster, Benedict Koh, Jean Lemaire, Olivia S. Mitchell, Greg Nini, Samuel Preston, Yong Yu, and participants in the BPUB 900 seminar at The Wharton School for their valuable comments and discussions. I am indebted to Jeff R. Brown and Olivia S. Mitchell for use of the code for generating utility-equivalent wealth values. All errors are my own. Please direct correspondence to hfong@wharton.upenn.edu.

This paper is posted at ScholarlyCommons. https://repository.upenn.edu/prc_papers/169

For more information, please contact repository@pobox.upenn.edu. 


\title{
Beyond Age and Sex: Enhancing Annuity Pricing
}

\begin{abstract}
Prices of standard annuity products in the United States do not currently reflect buyers' personal characteristics other than age and sex. I show that several readily-measurable risk factors can significantly increase explained variability in mortality outcomes in a proportional hazards framework and use them to construct alternative pricing schemes. Simulation results show that more detailed pricing may help reduce adverse selection in annuity markets because shorter-lived groups are made much better off (and thus enter the market) while longer-lived groups are made only slightly worse off (and thus remain in the market).
\end{abstract}

\section{Disciplines}

Economics

\section{Comments}

Fong is a doctoral student and S.S. Huebner Foundation Fellow at the Wharton School, University of Pennsylvania. All opinions are solely that of the author who acknowledges research support from the Pension Research Council/Boettner Center at The Wharton School. Without implicating them, I would like to thank Irma Elo, Dean Foster, Benedict Koh, Jean Lemaire, Olivia S. Mitchell, Greg Nini, Samuel Preston, Yong Yu, and participants in the BPUB 900 seminar at The Wharton School for their valuable comments and discussions. I am indebted to Jeff R. Brown and Olivia S. Mitchell for use of the code for generating utilityequivalent wealth values. All errors are my own. Please direct correspondence to hfong@wharton.upenn.edu. 


\title{
Beyond Age and Sex: Enhancing Annuity Pricing
}

\author{
Joelle HY. Fong
}

June 2011

\author{
PRC WP2011-05 \\ Pension Research Council Working Paper \\ Pension Research Council \\ The Wharton School, University of Pennsylvania \\ 3620 Locust Walk, 3000 SH-DH \\ Philadelphia, PA 19104-6302 \\ Tel: 215.898.7620 Fax: 215.573.3418 \\ Email: prc@wharton.upenn.edu \\ http://www.pensionresearchcouncil.org
}

Fong is a doctoral student and S.S. Huebner Foundation Fellow at the Wharton School, University of Pennsylvania. All opinions are solely that of the author who acknowledges research support from the Pension Research Council/Boettner Center at The Wharton School. Without implicating them, I would like to thank Irma Elo, Dean Foster, Benedict Koh, Jean Lemaire, Olivia S. Mitchell, Greg Nini, Samuel Preston, Yong Yu, and participants in the BPUB 900 seminar at The Wharton School for their valuable comments and discussions. I am indebted to Jeff R. Brown and Olivia S. Mitchell for use of the code for generating utility-equivalent wealth values. All errors are my own. Please direct correspondence to hfong@wharton.upenn.edu. Opinions and errors are solely those of the authors and not of the institutions providing funding for this study or with which the authors are affiliated. Copyright 2011 (C) Pension Research Council of the Wharton School of the University of Pennsylvania. All rights reserved. 


\title{
Beyond Age and Sex: Enhancing Annuity Pricing
}

\begin{abstract}
Prices of standard annuity products in the United States do not currently reflect buyers' personal characteristics other than age and sex. I show that several readily-measurable risk factors can significantly increase explained variability in mortality outcomes in a proportional hazards framework and use them to construct alternative pricing schemes. Simulation results show that more detailed pricing may help reduce adverse selection in annuity markets because shorter-lived groups are made much better off (and thus enter the market) while longer-lived groups are made only slightly worse off (and thus remain in the market).
\end{abstract}




\title{
Beyond Age and Sex: Enhancing Annuity Pricing
}

\author{
Joelle HY. Fong
}

How annuities are priced is of central concern to retirement decision-planning for individuals, and also for defined contribution plans. Annuities offer valuable longevity insurance against outliving one's assets by providing a periodic income for life in exchange for an upfront premium. But currently in U.S. and Canada, prices of standard retail annuities do not reflect buyers' personal characteristics other than age and sex. This lack of information in prices generates two concerns. Firstly, because insurers do not account for individual economic or health status, people who anticipate living longer can self-select into annuities. Empirical studies have shown that adverse selection exists in annuity markets (Mitchell et al. 1999; Finkelstein and Poterba 2002). Secondly, it may lead to consumer perception that standard annuities are only priced for those in very good health (Stewart 2007; Brown and McDaid 2003). Negative consumer perception may frustrate policymakers' efforts to expand the use of these lifetime income instruments in employer-sponsored or government-run defined contribution plans around the world.

The notion of using more risk-classes to price standard retail annuities has gained support in recent years, largely motivated by an interest in growing the life annuity market. In an OECD study, Stewart (2007) suggests that annuity providers should be permitted to put people into different risk categories to allow for more pricing flexibility, reduce adverse selection, and increase consumers' trust in the pricing of annuity products. In fact, some major U.K. insurers have already begun using more personal characteristics such as client postcodes, marital status, and tobacco use, to price their standard payout annuities (Banking Times 2008). Nonetheless, these insurers are still struggling to define suitable pricing factors and work out the specifics (e.g. how to classify individuals who have two addresses). Given the precedence of risk-class pricing in life insurance and auto insurance, there is strong reason to believe that using more indicators of life expectancy, other than just sex and age, might be a natural evolution for retail annuity pricing. 
A large literature focuses on measuring the money's worth of annuities and reports, in a voluntary purchase environment, that annuitants obtain higher money's worth from annuity purchase than would the population if all were to purchase. ${ }^{1}$ This difference is quantified as the adverse selection cost. For example, Mitchell et al. (1999) estimates adverse selection cost to be about $54 \%$ of total loadings in the U.S. annuity market. In smaller annuity markets such as Singapore and Australia, estimates are also about 40 to 50\% (Fong et al. 2011; Doyle et al. 2004). Researchers have also shown that the extent of adverse selection observed in actual annuity markets depends on market type and product line. In particular, adverse selection is lower in compulsory markets as compared to voluntary ones, and also for annuities with period-certain guarantees as compared to those without guarantees (Finkelstein and Poterba 2002). ${ }^{2}$ Since information asymmetry arises because annuity buyers have "private" information about their mortality, the extent of adverse selection is likely to depend on pricing structures as well. It would seem that incorporating more personal characteristics in annuity pricing can help reduce adverse selection. Yet investigations of this kind are challenging for a number of reasons, including the need to construct plausible alternative pricing schemes, and having to model selection effects as pricing structures evolve.

The primary contribution of this paper is to use longitudinal micro data from the Health and Retirement Study (HRS) to develop alternative pricing structures and examine their impact on annuitization values across different demographic groups. Using a proportional hazards framework, I show that several readily-measurable risk factors can significantly increase explained variability in mortality outcomes. Adding the ten best-ranked factors to age and sex increases explained variation from $6.7 \%$ to $29.7 \%$. Assuming one or more of these pricing factors are adopted, I then simulate annuity prices for a variety of pricing schemes and compute the annuitization value accruing to a given demographic group under each scheme. Both the financial value and utility value of longevity insurance are assessed.

The impact of risk-class pricing on adverse selection is not straightforward. The need to collect more information may result in insurers imposing higher administrative fees. Even if a

\footnotetext{
${ }^{1}$ See for example, Mitchell et al. (1999) and Finkelstein and Poterba (2002).

${ }^{2}$ In 1998, the U.K. compulsory annuity market was much larger than the voluntary market; there is less scope for adverse selection in the former because participants in defined contribution occupational, or personal, pension plans must annuitize their resources (Finkelstein and Poterba 2002). Less adverse selection is observed for annuities with longer period-certain guarantees primarily because of shorter-lived individuals self-select into annuities with longer guarantee periods.
} 
rating class is justified, insurers may not have the flexibility to introduce large disparity in prices in actual markets. Annuity purchase decisions are also influenced by many factors other than just the financial return from annuities. It is, however, widely believed that more detailed pricing reduces information asymmetries between the insurer and the insured and thus will reduce adverse selection. My paper contributes to this discussion by highlighting two effects that may occur when more pricing factors are implemented: (1) shorter-lived groups will be sufficiently induced to buy annuities and enter the market, and (2) longer-lived groups will still be incentivized to stay in the annuity market. Overall, this will allow annuity markets to grow causing the extent of adverse selection to fall. ${ }^{3}$

Compared to prior population-based studies on mortality, this paper is distinguished by its effort to understand how several less conventionally-used variables relate to retirement mortality. For instance, birth region is a truly exogenous demographic variable but it is seldom used in empirical studies. Recently, Sloan et al. (2010) find that being foreign-born is associated with lower mortality hazards. ${ }^{4}$ Cognition is another interesting variable to examine in relation to older adults. For example, Mehta et al. (2003) find cognitive function to be independently associated with mortality among elderly adults above age 70 in the Asset and Health Dynamics Among the Oldest Old (AHEAD) study. This study is therefore informative regarding the potential for such less -conventional variables to serve as suitable pricing factors for annuities.

Section 1 outlines some possible impediments to risk-class pricing, and highlights recent efforts by commercial insurers to incorporate more personal characteristics in annuity pricing. Section 2 describes the data and methodology. Section 3 presents results from the proportional hazards regressions, and demonstrates how risk-classification sharpens age-at-death predictions. Section 4 reports simulated annuity premiums and assesses the financial value of annuities accruing to various demographic groups under different pricing schemes. Section 5 examines the value of annuities on a utility-adjusted basis in an environment of mortality heterogeneity. Section 6 concludes.

\footnotetext{
${ }^{3}$ Point (2) is necessary because the co-existence of longer-lived and shorter-lived groups is what distinguishes the standard annuity market (which is the focus of this paper) from an impaired annuity market where detailed annuity underwriting is already in place. Impaired annuities are discussed later in Section 1.1.

${ }^{4}$ Several studies controlled for current residence instead, which is possibly endogenous to current mortality. For example, Dupre et al. (2009) controlled for whether a respondent lives in the South. Sloan et al. (2010) included dummies for whether a subject lives on a farm, and whether he is foreign-born. Glymour et al. (2008) study the risk of first stroke among the HRS participants and specifically incorporated an indicator for Southern birth-state (also known as the stroke belt).
} 


\section{$1 \quad$ Background}

\subsection{Pricing Structure of Annuities}

The extent of underwriting varies across different types of annuities. ${ }^{5}$ At one end of the spectrum are pension annuities and the U.S. Social Security pension system. Job-based pension annuities are priced based on age (Brown 2002; U.S. Supreme Court 1988). ${ }^{6}$ Similarly, benefit payouts under the U.S. Social Security program are also purely based on the age of annuitization. ${ }^{7}$ Any differences along gender, racial, or education lines are disregarded. In contrast, retail annuity providers are permitted to use gender-specific pricing. In U.S. and Canada, standard retail annuities are priced based on age, sex, and the amount of money annuitized (Brown and McDaid 2003). Females typically pay a higher premium than males under this pricing structure because they are expected to live longer. In addition, Stewart (2007) reports that differential pricing policy between races is allowed in the European Union.

At the other end of spectrum are so-called impaired or enhanced annuities. Impaired annuities were introduced in the U.K. around 1995 and since then, this market segment has grown in size and importance. ${ }^{8}$ Impaired annuities are sold to retirees with profiles of high mortality (e.g. those in poor health) or those in nursing home care. It is estimated that as many as 40 percent of U.K. annuity purchasers can qualify for impaired annuities (The Investors Chronicle 2008). Underwriting for impaired annuities is via a health questionnaire (mild medical conditions), and a medical report (for more severe medical conditions such as heart attack, or cancer). Individuals who qualify for such annuities enjoy lower premiums. In U.S. and Canada, impaired life annuities are available but the market is small (Rusconi 2008; Brown and McDaid

\footnotetext{
${ }^{5}$ Life insurance companies collect information about individuals before deciding at what price to sell insurance to them. Applicants for insurance are individually interviewed (often by means of a written questionnaire), and sometimes examined by a medical practitioner. This process is called "underwriting".

${ }^{6}$ In City of Los Angeles v. Manhart, 435 U.S. 702 (1978), it is ruled that section 703(a)(1) of the Civil Rights Act of 1964 barred requiring women to contribute more than men to pensions to receive the same benefits. Later, a landmark Supreme Court decision in Florida v. Long similarly ruled that only unisex mortality lifetables may be employed in the pricing of pension annuities (US Supreme Court 1988).

${ }^{7}$ Social Security refers to the federal Old Age, Survivors and Disability Insurance (OASDI) Program, which is a comprehensive federal benefits program developed in 1935. The Social Security is a pay-as-you-go defined benefit pension system funded through dedicated payroll taxes, and benefit payments are made monthly to eligible individuals.

${ }^{8}$ Impaired annuities were introduced in the U.K. around 1995 by a company called Stalwart, which was later acquired by GE Capital (Bestwire 2010). Impaired annuity sales in the U.K. totaled £1.26 billion ( $€ 1.51$ billion) in the first six months of 2010. The full-year sales figure for 2009 was $£ 1.78$ billion, up from $£ 419.6$ million in 2001. Companies currently active in this market segment include Aviva, Canada Life, and Legal \& General.
} 
2003). Such annuities are only offered to individuals who can prove that they are in substandard health via a medical certificate.

The focus of this paper is the pricing of standard annuities. Although impaired annuities represent a growing niche in the annuity markets, they are limited to people who are of substandard health and thus of less relevance to say, an average retiree of average health who wishes to annuitize. The current pricing structure of standard retail annuities leaves much room for pause. This is because there are no obvious regulatory barriers to risk-classification (aside from using sensitive factors like race), and the insurance industry has a ready technology given their experience in the life insurance business.

One possible impediment may be costs. According to a Deloitte 2008 benchmarking study of 15 U.S. life insurers, an insurer typically spends approximately one month and several hundred dollars underwriting each applicant (Batty et al. 2010). While a few hundred dollars is not necessarily cost-prohibitive for life insurance products, it may be so for annuities. This is because annuities are relatively low-margin financial products, and insurers already view them as not very profitable relative to other product lines (Orth 2008). The underlying reason is due to very thin annuity markets. Existing research shows that the voluntary markets for individual immediate annuities in U.S., Australia, France, Germany, Italy and Japan are small (MacKenzie 2006; Brown 2001; Knox 2000). ${ }^{9}$ In addition, underwriting can be costly in terms of buyer fraud. Brown and McDaid (2003) provide the analogy of an applicant who smokes cigarettes for a period of time to get better annuity rates. Likewise, an applicant may exaggerate her health problems to qualify for lower premiums.

A second reason pertains to the lack of annuitant mortality data. To justify placing applicants into different pricing categories, there must be some actuarial basis indicating how mortality differs among those groups. Because the insured population is not the same as the noninsured population, insurance companies typically collect mortality experience of their applicants over a long period of time to facilitate such analysis. A case in point is the smoker/nonsmoker rating class used in the life insurance markets. In the 1960s, U.S. life insurance companies still charged the same rates to smokers and nonsmokers (SOA 1983), and it

\footnotetext{
${ }^{9}$ Several reasons have been suggested to explain the lack of demand for annuities (or the so-called annuity puzzle). Among the explanations are the role of adverse selection and administrative load factors (Mitchell et al. 1999; Finkelstein and Poterba 2002), bequest motives (Abel and Warshawsky 1988), the ability of risk-pooling within families (Kotlikoff and Spivak, 1981), and precautionary savings.
} 
was only after two decades that sufficient mortality experience emerged enabling actuaries to construct smoker/nonsmoker mortality tables. These developments in turn led to cigarette smoking being adopted as a rating class in life insurance policies. ${ }^{10}$ Similarly, substantial information on annuitants needs to be collected before mortality differentials amongst riskgroups with different demographic characteristics can be analyzed. Thus far, this has been an uphill task because of the very thin annuity markets. Stewart (2007) reports that a surprisingly large number of developed countries still lack the demographic data necessary to construct accurate mortality projections for annuitants, and use lifetables from other countries with richer annuitant experience such as U.K. and U.S. ${ }^{11}$

Regulatory restrictions may also play a role. For instance, sex has long been employed as a rating class in life insurance whereby women pay lower premiums than men because statistics show that women live longer. Yet in March 2011, the European Court of Justice ruled that the widespread practice of charging men and women different rates for insurance is illegal and has set out to overhaul the pricing of insurance policies across Europe (WSJ.com 2011). Britain and other EU states will enforce the ban on using sex as a pricing factor on all new insurance contracts, including annuities and motor insurance, entered into on or after 21 Dec 2012 (Reuters 2011). The U.S. prohibits using sex in job-based pension annuities although it is allowed as a rating class for retail annuities.

\subsection{Movement towards Risk-based Pricing}

The notion of using more risk-classes to price standard retail annuities is largely motivated by an interest in growing the life annuity market. In an OECD study, Stewart (2007) suggests that insurers should be permitted to risk-categorize annuitants to allow for more pricing flexibility and to increase consumers' trust in the pricing of annuity products. Similarly, Brown and McDaid (2003) stress that workers will ideally want to annuitize at fair-market rates that

\footnotetext{
${ }^{10}$ Smoker/nonsmoker rates for life insurance policies are also successfully introduced with new underwriting assistance such as blood tests (Brown and McDaid 2003).

${ }^{11}$ Stewart (2007) also suggests that segmented mortality data on annuitants can be collected by governments, or alternatively, by a cooperative arrangement among insurers willing to cost-share. Currently, U.S. insurers typically use the RP-2000 annuitant lifetable as a reference (McCarthy and Mitchell 2010). The RP-2000 annuitant life table is provided by the Society of Actuaries, and constructed based on actual annuitant experience from plan years 1990 through 1994. In U.K., pensioner and annuitant lifetables are available from the Continuous Mortality Investigation Committee, and are prepared based on actual annuitant experience collected from U.K. insurance companies. Annuitant lifetables are distinct from actuarial tables used in valuing life insurance policies (e.g. the 2001 Valuation Basic Table).
} 
reflect their personal mortality profiles. Evidence from other insurance markets suggests that effective underwriting can also alleviate adverse selection problems. For instance in life insurance, Cawley and Philipson (1999) present convincing evidence that life insurers may be better at identifying mortality risk than individuals themselves. Similarly, McCarthy and Mitchell (2010) find that U.S. and U.K. insurers' screening of poorer risks in life insurance reduces asymmetric information held by policyholders. In auto insurance, Chiappori and Salanie (2000) conclude that "...the information at the [auto insurers] company's disposal is extremely rich and that, in most cases, the asymmetry, if any, is in favor of the company."

In the U.K., commercial insurers have begun using risk-based pricing for standard annuities. In 2008, Norwich Union - an insurer with about 10 percent market share - started using client postcodes, marital status, and tobacco use, to price its annuities (Banking Times 2008). Other major insurers like Prudential, and Legal \& General, have also justified using postal codes on the premise that those who reside in more affluent areas tend to be longer-lived. In fact, U.K. market players observe that the differentiation between impaired annuities and standard (non-impaired) annuities have started to blur (Bestwire 2010). These developments represent a positive step towards annuity risk-class pricing. Going forward, there is strong reason to believe that the movement towards risk-class pricing for standard annuities may be sustained and eventually extend to the rest of the world.

Nonetheless, there is currently no consensus on which risk-classes may be most suitable. While insurers have experience in underwriting life insurance policies, it remains the case that some conventionally-used factors are difficult to verify, for example lifestyle habits or participation in hazardous activities like sky diving. Certain risk factors are also mutable, such as smoking, which leaves insurers susceptible to buyer fraud. ${ }^{12}$ In addition, there are factors not explored in other forms of insurance pricing that tend to help explain longevity; for instance, several studies have found that intelligent people live longer (Deary 2008; Hauser and Palloni 2010). Notably, Brown and McDaid (2003) identify 10 potential risk-classes, including education, income, and occupation, race, health behavior, and religion, based on a literature

\footnotetext{
${ }^{12}$ Mutable factors are those which can be modified by the individual, and thus hard to verify. This is in contrast to fixed factors. See Bond and Crocker (1991) for a detailed analysis of the implications of mutable risk classification characteristics. In the context of annuity policies, an analogy is a person who starts to smoke heavily in order to pass of as someone who is shorter-lived in order to qualify for a lower annuity premium.
} 
review of mortality studies. ${ }^{13}$ Among this list, however, several factors are possibly correlated while other factors (e.g. health behavior) are not easily measurable. Also, the study did not give a sense of which variables are more important than others.

The next section develops a risk-classification approach by picking out several "readilymeasurable" risk factors that may explain longevity. "Readily-measurable" factors includes exogenous variables (like birth region, race, and parental factors), or predetermined factors (like education), or objectively-measured factors (like body mass index and cognition). These factors are desirable from an insurer's standpoint because they are not too costly to collect, easy-toverify, and also tend to be difficult to fake. This helps to address issues such as underwriting costs and buyer fraud.

\section{$2 \quad$ Data and Methodology}

To study predictors of mortality among adults near retirement, I use data from the Health and Retirement Study. ${ }^{14}$ The HRS is an ongoing panel study of Americans over the age of 50 conducted every other year since 1992, and it features questions on health, economic status, retirement plans, cognition, pensions, family structure, and expectations. The baseline birth cohort interviewed comprised respondents born 1931 - 1941; other cohorts were added in later waves. This paper focuses on individuals in the baseline cohort who were surveyed biannually from 1992 through 2008, providing nine waves of panel data. ${ }^{15}$ The initial response rate in 1992 is $82 \%$, and subsequent reinterview response rates are well above $90 \%$ on average (HRS 2008). Out of a possible sample of 9,281 respondents, I exclude 11 persons because of faulty or incomplete information on survival status, and 223 respondents $(2.4 \%)$ with no available followup data. The analysis sample is consequently restricted to 9,047 respondents. Appendix Table 1 provides basic descriptive statistics.

\footnotetext{
${ }^{13}$ Base on a review of 45 empirical papers, Brown and McDaid (2003) highlight 10 factors that seem important in predicting mortality after retirement, in addition to age and sex. They are (in no particular order): race, education, income, occupation, marital status, religion participation, health behaviors (lifestyle and use of health services), smoking, alcohol, and obesity.

${ }^{14}$ See Juster and Suzman (1995) and HRS (2008) for details about the HRS multistage sample design, enrollments, implementation, and response rates.

${ }^{15}$ The HRS sample cohort (those first interviewed in 1992) comprised 12,521 respondents, including spouses (HRS Tracker 2009, p.19) After excluding 2,770 respondents not born between 1931 and 1941, and 470 proxy respondents, the reduced sample is 9,281 .
} 


\subsection{Measures}

Survival status and duration. All-cause mortality is the outcome of interest. HRS tracking efforts, along with a linkage to the National Death Index, allows mortality to be measured very accurately between survey waves. Death is defined as the "time-to-failure" event, based on the reported month/year of death and respondents' wave-by-wave vital status in the Tracker 2008 (v1.0) file. ${ }^{16}$ No information on the cause of death was obtained. In the small number of cases where the exact date of death is unknown ( $n=10$ with no information and another $n=5$ with death year only), a death year is imputed based on the respondent's specific wave-by-wave vital statuses, and a death month using a random integer from 1 to $12 .{ }^{17}$ If an individual is known to be alive in a given year, her survival status is carried back if it is missing in earlier waves. Subjects who cannot be identified as deceased, or who survived through 2008 are considered censored. Event variables indicating failure by wave is coded " 1 " if the individual died in that wave, " 0 " if the individual was alive and responded to an interview, and "missing" otherwise. ${ }^{18}$ All time variables including interview dates and death dates are expressed in months.

Age and sex. The initial risk variables of interest are those currently used in annuity pricing: age and sex. Both are defined at baseline and available from Tracker 2008. In particular, baseline age (representing birth cohort) is modeled as a continuous variable, and separately as categorical dummies, to test the difference in effects. Three sets of risk adjustments are then introduced to empirically determine their associations with mortality: conventional exogenous factors, less-conventional exogenous factors, and conventional endogenous factors. ${ }^{19}$

Conventional, readily-measurable factors. These include race (white/nonwhite), education ( $\geq 12 /<12$ years), whether married (no/yes), prior health history, and BMI (underweight,

\footnotetext{
${ }^{16}$ For the 1,905 failure events, $88.2 \%$ (or 1,680 cases) of the death years are obtained from HRS records, $11.3 \%$ (215) from NDI records, and $0.5 \%$ (10) imputed based on the wave-by-wave vital status. I rely primarily on the year/month of death obtained by HRS through interviews with surviving spouses, or exit interviews with surviving relatives. Where exit interviews are either not obtained, or incomplete, I use the NDI information also available from the HRS Tracker file. This procedure is consistent with HRS' advice that both sources of information (namely HRS and NDI) should be used to classify vital status in any analysis (HRS Tracker 2009, p. 12). In addition, HRS also seeks matches to the NDI for persons who were reported as deceased or who are not known to be alive through contact during tracking. Accordingly, I rely on the NDI alive/deceased flags, and death match scores to verify respondent vital status in 2008.

${ }^{17}$ These respondents were assumed to have died in the year between the two-year interval where their vital status switched from 'alive (or presumed alive)' in one wave to 'dead' in the next wave.

18 The event variable is coded "missing" as long as there was no response in a wave. This could be because respondents have permanently attrited from the study, or they failed to respond to interview during a particular wave but were known to be alive in a later wave. For the latter, their alive status is not imputed into the "missing" since I have no information on the time-varying covariates in that missing wave.

${ }^{19}$ These variables are all obtained from the RAND version J dataset (RAND 2010).
} 
normal (ref.), overweight, and obese). They are so-called conventional because these sociodemographic variables are commonly used as controls. ${ }^{20}$ The correlations between race and mortality, and education and mortality are well documented (Preston et al. 1996; Sorlie et al. 1992; Deaton and Paxson 2001; Kitagawa and Hauser 1973). In general, these correlations work in the direction that whites live longer than blacks, and more highly-educated live longer than less-educated individuals. For older individuals near retirement, it is posited that education and marital status are predetermined factors. Educational attainment is a reasonable proxy for lifetime financial resources, and appropriate since other social-economic status (SES) measures (current income, current wealth, and current occupation) are probably endogenous. Likewise, I control on prior health history instead of subjective self-assessments of current health. ${ }^{21}$ Health history is obtained from doctor-diagnosed disease conditions (whether a doctor ever told them they have chronic diseases such as hypertension, diabetes, arthritis, chronic lung disease, stroke, or heart attack). Prior literature suggests that such "ever-have" disease conditions are highly predictive of mortality. ${ }^{22} \mathrm{BMI}$ is also included since it can be measured objectively and easily, and is highly relevant given that a current issue of interest is how obesity relates to mortality and morbidity among older adults. ${ }^{23}$

Unconventional, readily-measurable factors. These include birth region (Northeast (ref.), Midwest, South, West, Foreign-born), cognition scores (continuous variable), parental education $(\geq 12 /<12$ years), and parental longevity. Birth place/region is seldom investigated as a predictor of mortality possibly because it is not available in many datasets. Most studies using HRS data did not control for this variable; Sloan et al. (2010), however, find that being foreign-born is associated with lower mortality hazards. Similarly, parental SES factors are not commonly used

\footnotetext{
${ }^{20}$ For instance, Idler and Angel (1990), Hurd and McGarry (2002), Glymour et al. (2008), and Sloan et al. (2010).

${ }^{21}$ Some studies have shown that objective measures are better predictors of mortality than subjective measures. For example, using a broad-based sample of U.S. adults aged 25-74 years from the National Health and Nutrition Examination Survey, Idler and Angel (1990) find that age, race, smoking, unemployment, alcohol use, illness symptoms, and marital status, are more predictive of survival than either self-assessed health.

${ }^{22}$ Using waves 1 and 2 of the HRS, Hurd and McGarry (2002) find that ever-have disease conditions especially cancer, heart attack, stroke, and diabetes to be highly predictive of mortality among individuals age 46-65. The study also shows low/high BMI to be associated with increased mortality although both variables were not statistically significant in the logit regressions. Chronic illnesses and categorical variables for BMI are similarly used to predict mortality for the HRS sample in other studies (e.g. Dupre et al. 2009, and Siegel et al. 2003). Although these variables are self-reported in the HRS survey, they are still arguably objective since weight and height are anthropometric measures, and the ever-have disease condition question is phrased in terms of a doctor diagnosis.

${ }^{23}$ The selected BMI categories are based on the widely-adopted World Health Organization definition of underweight $(\mathrm{BMI}<18.5)$, normal weight $(18.5 \leq \mathrm{BMI}<25)$, overweight $(25 \leq \mathrm{BMI}<30)$, and obese $(\mathrm{BMI} \geq 30)$. See SOA (2010) for an excellent review of empirical studies on obesity and its relation to mortality and morbidity.
} 
by researchers perhaps because adult mortality is believed to be better predicted by personal factors. Nonetheless, parental longevity has been shown to affect subjective survival expectations which in turn predict mortality (e.g. Hurd and McGarry 2002). Thus I control for parental education as well as parental longevity since they are exogenous and may turn out to be suitable risk-classes. ${ }^{24}$

Another explanatory variable of interest is cognitive ability, since it has been demonstrated that intelligent people live longer (Deary 2008). Among the various pathways proposed are that people with higher intelligence may be more well-organized, conscientious individuals; they may also tend to be more educated, work in healthier environments, and engage in healthier behavior (do not smoke, exercise, better diets, avoid accidents). Thus, cognition is a plausible risk-class for annuitants (who tend to be older adults) and an added advantage is that cognition is objectively-measured in the HRS. ${ }^{25}$

Conventional, endogenous factors. Prior research has emphasized the importance of selfratings and self-assessments of health in predicting mortality (e.g. Idler and Benyamini 1997). Despite endogenous factors not being the focus of this paper, it is important to assess how their inclusion may affect the predetermined and/or exogenous covariates. Specifically, I use selfreported health (excellent (ref.), very good, good, fair, and poor), whether currently smoke (no/yes), ever smoked, and ever drink.

\subsection{Estimation Models}

Proportional hazard $(\mathrm{PH})$ regression analysis is used to (1) assess the bivariate relationship of each additional predictor variable with longevity, controlling for age and sex; and

\footnotetext{
${ }^{24}$ Although HRS contains data on the parents' vital status, it is dependent on the respondent's age at time of interview and thus not reflective of parental longevity. To construct the parental longevity variables, I create a continuous variable using parent's current age (or age at death if deceased) minus sex-specific life expectancy, divided by 10 . The life expectancy used for fathers is age 65 , which is an average of the life expectancies of a 15year old male and 30-year old male in 1931 and 1941, weighted by the respondent sample composition. The life expectancy used for mothers is age 69. For example, mother's longevity will be negative if the mother died before 69 but positive if the mother survived past 69 .

${ }^{25}$ The HRS is one of the first national health surveys to measure cognitive health at the population level, and cognitive tests are administered based on well-validated measures developed from psychological research on intelligence and cognition (Herzog and Wallace 1997). In this paper, cognition scores are obtained from the Imputation of Cognitive Functioning Measures 1992-2006 (v1.0) dataset which contains imputations for cognitive functioning data for HRS 1992 through 2006 (Fisher et al. 2009). In 1992 and 1994, only questions pertaining to a respondent's memory skills (immediate / delayed word recall) were asked. As such, the cognition score defined at baseline is the 1992 memory status score (scale 0-40). From 1996 onwards, the HRS included additional questions pertaining to a respondent's mental status (e.g. Serial 7s test, backwards counting etc.).
} 
(2) construct a multivariate equation estimating the independent effects of the more detailed list of prognostic factors. An important strength of the hazard framework is its ability to properly treat right-censored data. Respondents who survived the entire observational window from baseline to 2008 were treated as censored after their 2008 wave interview. For others not known to be dead but who attrited from the study at various time points, their data are censored as of the last interview date. Consider the general form of the $\mathrm{PH}$ function:

$h\left(t \mid \boldsymbol{x}_{\boldsymbol{j}}\right)=h_{0}(t) \cdot \exp \left(\boldsymbol{x}_{\boldsymbol{j}} \boldsymbol{\beta}\right)$

where $h\left(t \mid x_{\boldsymbol{j}}\right)$ is the resultant hazard rate for the $j^{\text {th }}$ subject in the data, given survival time $t$ and the subject's vector of covariates $\boldsymbol{x}_{\boldsymbol{j}}$. It is also called the mortality risk (or force of mortality). $h_{0}(t)$ is the baseline hazard function (i.e. hazard when all independent variables are set to their reference categories), and $\boldsymbol{\beta}$ is the vector of regression coefficients to be estimated. Equation (1) states that the death hazard that subject $j$ faces is multiplicatively proportional to the hazard everyone faces, modified by his personal characteristics expressed as a vector $\boldsymbol{x}_{\boldsymbol{j}}$.

Within the general class of PH models, I specifically estimate two types. First, the Cox (semi-parametric) model is employed because of its flexibility (it does not require assumptions about the underlying hazard function); the shape of the hazard function $h_{0}(t)$ is unconstrained. Cox models have been widely applied in previous mortality studies using the HRS data (e.g. Sloan et al. 2010; Dupre et al. 2009; Lee et al. 2008; Siegel et al. 2003; and Mehta et al. 2003). Second, I consider a parametric alternative by imposing a Gompertz form on the underlying hazard function. It is well-documented that in past-middle adult ages (age 40 - 90) the mortality curve displays a regular and nearly exponential increase that can be represented by the Gompertz function (Gompertz 1825; Preston et al. 2001; Bongaarts and Feeney 2002). ${ }^{26}$ Thus, the Gompertz form is suitable since the sample of HRS respondents is age $51-77$ over the observational window. ${ }^{27}$

\footnotetext{
${ }^{26}$ The Gompertz model might actually underestimate mortality at ages under 40 and overestimate mortality at the oldest ages over 80 or 90 . The Makeham-Gompertz and logistic models have been proposed to address these deviations. Nonetheless, for many purposes, the Gompertz model provides a satisfactory fit to adult mortality rates for ages between 40 and 90. I refer interested readers to Preston et al. (2001).

${ }^{27}$ Using Cox-Snell (Cox and Snell 1968) residuals, I also find that the 'Gompertz' form fits the data best compared to other parametric forms (e.g. the 'Weibull', 'Log-logistic', and 'Lognormal'). The cumulative hazard function (estimated with Cox-Snell residuals using the Gompertz form) lies very close to the 45 -degree reference line.
} 
The Gompertz PH model is implemented with the following hazard and survivor functions:

$h\left(t \mid \boldsymbol{x}_{\boldsymbol{j}}\right)=\exp (\gamma t) \exp \left(\boldsymbol{x}_{\boldsymbol{j}} \boldsymbol{\beta}\right)$,

$S(t)=\exp \left\{-\mathrm{e}^{\boldsymbol{x}_{\boldsymbol{j}} \boldsymbol{\beta}} \gamma^{-1}\left(\mathrm{e}^{\gamma t}-1\right)\right\}$,

where $\gamma$ is the additional parameter to be estimated from the data. Empirically, I find that the Gompertz function fits the survival function for both sexes exceptionally well in part because the sample respondents are all above age 50; most however have not reached the advanced ages of 80 or 90 by the 2008 wave. Results from the Cox regressions are nearly identical to those from the Gompertz approach (further evidence that the Gompertz function appropriately parameterizes the underlying baseline hazard); hence I present only the latter. Moreover, the parametric approach allows us to obtain more efficient estimates of the coefficients than the semi-parametric model, because it exploits all information in the data; the Cox model only compares subjects at failure times. Statistical analyses are conducted using STATA 11.0 software, ${ }^{28}$ and weighted to account for over-sampling of blacks, Hispanics, and Floridians in the HRS.

One important issue to consider in the estimation is whether the hazard functions for males and females have different shapes. If the hazards for sexes are not proportional, then subsequent estimations need to be separated by sex. Results from fitting stratified models reveal that the hazards are proportional and thus a combined analysis is reasonable. ${ }^{29}$ Furthermore, hazard plots for both sexes are nearly parallel over the entire follow-up period. Another concern might be the nonlinearity of age and the interaction of age with analysis time. ${ }^{30}$ Nonetheless, analyses not reported in detail here show that higher order age variables and time-age interaction

\footnotetext{
${ }^{28}$ See Cleves et al. (2010) for an overview of survival analysis using STATA's procedures.

${ }^{29}$ To test for differences in shape between the hazards for males and females, I include an ancillary gamma parameter in the Gompertz distribution to allow both the scale and shape of hazard to vary by sex (complete stratification). I find that coefficients do not differ, irrespective of whether we constrain the hazards to be of the same shape, or allow them to vary. This implies that the effect of sex on the shape of the hazard is not significant, up to a scale change. Stratification involving the Cox model leads to the same conclusion.

${ }^{30}$ Age may interact with follow-up time; for example, a respondent who is older at enrollment may be more likely to die during follow-up (Dickman et al. 2004). If so, then the proportional hazards assumption is not appropriate for the age covariate since the hazard ratio will differ according to analysis time. In this model, the age*t interaction term is not statistically significant, controlling for age and sex.
} 
terms are not significant ( $\mathrm{p}>.05)$. In order to properly estimate the baseline survivor function, the age variable is transformed so that the baseline hazard corresponds to a 50-year-old retiree. ${ }^{31}$

In what follows, I first consider a specification (call it "M1") with only information currently used by U.S. annuity providers i.e. age and sex. Then, the three blocks of additional prognostic factors are sequentially added to the PH model in the following order: "M2" adds the set of conventional, readily-measurable covariates; "M3" adds the block of less-conventional covariates; and finally "M4" adjusts for conventional, endogenous risk factors. In this way, any changes in the relation between the various control variables and mortality can be observed, while evaluating the fit of each specification.

\section{Results: Survival Analysis}

Of the sample of 9,047 HRS respondents, 6,547 survived, 1,905 died, and 595 permanently attrited by the 2008 wave. The 16 -year mortality rate is $21.1 \% ;^{32}$ the attrited group is added to the denominator because it is observed that the bulk of attriters had requested removal from the HRS survey in-person whilst alive. ${ }^{33}$ In comparison, the 1992 lifetable mortality rate (weighted to reflect sample composition) is $23.5 \%$. Mortality rates in the HRS sample are slightly lower than lifetable rates since HRS initially surveyed only the communitybased population, which excludes long-term care facility residents. Figure 1 shows that 70 percent of males and 78 percent of traced females survived the entire 16 years of follow-up. Also, the men's survivor curve lies below that of the women's, indicating that mortality risks are greater for males at every age. The observation that females have a better survival experience is consistent with observed longer life expectancies for women in the population at large. The survivor functions (Kaplan-Meier curves) in the Figure are also gently sloped which suggest that

\footnotetext{
${ }^{31}$ I use baseline age minus 50 . The origin from which the covariate is measured impacts the baseline cumulative hazard and survivor function because it changes how "all covariates equal zero" is defined. If age is unadjusted, the baseline hazard will correspond to a newborn.

32 This mortality estimate (spanning Waves 1 to 9) appears reasonable given that the overall cumulative mortality for the HRS sub-sample up to Wave 7 is $15.9 \%$ (HRS 2008). The confirmed mortality rate is $22.5 \%$ (excludes the attrited group from both the nominator and denominator).

${ }^{33}$ The Tracker file records the detailed result of each interview attempt as of the close of the field period by wave, although the coding across waves was inconsistent. From the 2002 wave, it classifies respondents' removal from the study according to these categories: respondent requests removal in person; request through informant, request through proxy, because tracking was exhausted, or because a proxy cannot be identified. I observe that a large percentage (above 93\%) had asked to be removed from the sample in-person, and only a handful of cases were lost to tracking. As a result, the extent of unaccounted deaths among the attriters in the sample is minimal.
} 
the increase in mortality risk over time is gradual. ${ }^{34}$ An important feature of the Kaplan-Meier curve is that it accounts for right-censoring, which occurs if a respondent withdraws from the study. The longest observation in this dataset survived 201 months (16.75 years), and was ultimately censored.

Figure 1 here

\subsection{Proportional Hazards Regressions}

Table 1 reports the results from fitting the Gompertz $\mathrm{PH}$ model for different sets of prognostic factors. The estimated hazard ratios (or odds ratios) give the partial effects of the explanatory variables on the odds of mortality. ${ }^{35} \mathrm{~A}$ hazard ratio larger than 1 indicates that an increased hazard (probability of death) is associated with the explanatory variable, and a hazard ratio less than 1 indicates that a decreased hazard is associated with the explanatory variable. Accompanying 95 percent confidence intervals are also reported. It is apparent from Table 1 that probability of death is significantly higher for males and older people. Specifically in Column (M1), being a male is associated with a $62 \%$ higher mortality risk $(\mathrm{p}<.01)$ as compared to a female, and aging each year beyond age 50 is associated with $9 \%$ increased risk. In addition, the partial effects show that age and sex continue to be significant predictors of mortality even when more covariates are added in subsequent specifications.

\section{Table 1 here}

A better way to evaluate these hazard ratios is in the context of the baseline hazard function since the absolute increase in mortality risk depends on the size of baseline hazard. Figure 2 illustrates the hazard functions of four individuals of different attributes. The solid line is the baseline hazard depicting the hazard rates for our baseline case: a female age 50 in 1992. Her instantaneous probability of death starts low at age 50 and increases to about .0011 by the time she is age 66 (in 2008). Turning to consider the case of a male who is also age 50 in 1992, the Figure shows that his hazard function lies just slightly above the baseline hazard. This is because although he faces 1.62 times more risk than the female, the baseline hazard is small such

\footnotetext{
${ }^{34}$ One reason might be that the deaths observed over the time window are of individuals who die before their life expectancies (age 79-81). The average observed death age is 66. In other words, the subjects have not reached their 'critical' years by the end of 2008 .

${ }^{35}$ For a categorical variable, the hazard ratio compares the (mortality) hazard rate for respondents with the factor to the hazard rate for those without it. For a continuous variable, the hazard ratio represents the increase in hazard associated with a single unit of change in the explanatory variable.
} 
that a $62 \%$ increase in risk does not create a large impact. In contrast, a 60-year old male has a hazard function that lies far above the baseline hazard. He faces about 3.84 times more the baseline case at any given point in time and has a hazard rate of .004 by the time he is age 76 (in 2008). More generally, the Figure shows closely parallel lines which support the proportionality assumption. The monotonically increasing functions are also consistent with the Gompertz parameterization.

Figure 2 here

Column (M2) adds race, education, whether married, prior health history, and weight all of which are highly significant $(\mathrm{p}<.001)$. Lower mortality hazards are associated with respondents who completed high school $(\mathrm{HR}=0.73 ; 95 \% \mathrm{CI}=0.66,0.82)$, or who are married $(\mathrm{HR}=0.69 ; 95 \% \mathrm{CI}=0.62,0.77)$. On the other hand, people who are nonwhite, underweight, or had chronic diseases such as lung disease, diabetes, and heart attack face higher mortality risks. ${ }^{36}$ In particular, being underweight (symptomatic of an underlying disease) increases the risk of death by 2.9 times as compared to the reference normal weight group. It may appear surprising that obesity $(\mathrm{BMI} \geq 30)$ is not associated with an excess risk of death. This is because the extent of obesity matters: several studies have shown statistically significant associations between allcause mortality and BMI in severely obese groups (BMI $\geq 35)$, but not for the mildly obese group. ${ }^{37}$ Overall, M2 has substantially better fit than M1: the Wald test statistic $\left(G^{2}\right)$ reported in the Table shows a six-fold increase and the difference is highly significant $(1,287,16 \mathrm{df}-191,2$ df $=1,096,14 \mathrm{df}, \mathrm{p}<.000){ }^{38}$

Column (M3) adds the set of less conventionally used variables, including birth region, cognitive score, and parental factors. A ten-point increase in cognitive score is associated with a

\footnotetext{
${ }^{36}$ Our reported hazard ratios are consistent with those in prior studies. For example, using a sample of HRS male respondents, Sloan et al. (2010) report hazard ratios of 0.945 for with high school education, 0.794 for married, 1.170 for blacks, 1.006 for baseline age, and 0.83 for foreign-born.

${ }^{37}$ Consistent with the findings here, prior studies that used HRS data did not find statistically significant differences in the mortality of overweight and mildly obese groups versus the normal weight group (Reuser et al. 2008, Mehta and Chang 2009). For example, Mehta and Chang (2009) find that respondents who are Class I obese (BMI 30-34.9) do not face excess mortality risk but those who are severely obese (Class II/III obesity with BMI $\geq 35$ ) do. That study concluded that obesity is not a significant cause of mortality in the HRS population because there are relatively few people who are extremely obese. Applying finer classes of obesity in this present paper, I find that the 'Class III obese' variable has a hazard ratio above one but the effect is not significant (results not presented).

${ }^{38}$ The test statistic is based on the chi-square test that at least one of the predictors' regression coefficients is not equal to zero in the model. It is also a measure of model fit - a larger statistic indicates better fit. In nested models, the model with more parameters will always fit at least as well as the one with fewer parameters. Whether the fuller model fits significantly better and thus preferred, can be determined by deriving the p-value of the difference between the test statistics. The Wald chi-square statistic (a variant of the likelihood-ratio chi-square) is used as it accounts for the clustering across observations for the same subject.
} 
$26 \%$ lower mortality hazard ( $\mathrm{p}<.01)$. Also significant is birth region: respondents not born in the US, or born in the West region, face $26-37 \%$ less mortality risk as compared to those born in the Northeast region of North America. Results also show that father's longevity is predictive of mortality; a respondent whose father survives 10 years past age 65 faces 5\% lower hazard. Interestingly, a stepwise procedure (not reported in detail here) reveals that the inclusion of cognitive score is the key reason for the diminished effect of race on mortality (odds ratio falls from $1.18, \mathrm{p}<.01$ to $1.14, \mathrm{p}<.05)$. This suggests that nonwhite HRS respondents are likely to have lower cognitive scores and to die younger. ${ }^{39}$ If so, this enhances the attractiveness of cognition as pricing factor since not only is it objectively-measured, it also act as a proxy for an important demographic characteristic like race. The overall improvement in fit (Wald test statistic) is modest but statistically significant $(\mathrm{p}<.000)$. In essence, model M3 represents the complete specification with the proposed set of readily-measurable factors that can be used to price annuities, in addition to age and sex.

The set of endogenous controls are introduced in Column (M4) to test how their inclusion affects estimates of previously-controlled covariates. Results show that self-rated health and smoking are significant $(p<.01)$. In particular, a person who reports "poor" health faces triple the risk ( $\mathrm{HR}=3.02 ; 95 \% \mathrm{CI}=2.38,3.81)$ of someone who reports "excellent" health. The inclusion of self-rated health also makes the race and education variables lose statistical significance. ${ }^{40}$ Interestingly, pairwise correlation analyses reveal that respondents who rate their own health poorly tend to be better educated, and are white (rather than black or Hispanic). This observation concords with Dowd and Zajacova (2007) who find that individuals across SES strata differ in how they evaluate their health. In particular, lower health self-ratings are more strongly associated with mortality for adults with higher education and/or higher income. The useful takeaway here is that self-rated health is not likely to be useful as an additional pricing factor - it is subjective and its explanatory power is derived from existing SES factors. Current smoking increases hazards by $76 \%$. While its strong independent effect on mortality enhances its

\footnotetext{
${ }^{39}$ This is consistent with the findings in Rodgers et al. (2003). Using the 1993 and 1998 waves of the AHEAD sample in the HRS, their regression analysis on cognitive score show that being African-American is associated with an estimated decline of about 0.49 points on the total cognitive score per year, while being Hispanic is associated with a 0.35 points decrease.

${ }^{40}$ A stepwise procedure (not reported in detail) shows that the addition of self-rated health to the model has the greatest impact on existing covariates. In relation, the pairwise correlations are 0.19 (self-rated health and nonwhite) and -0.32 (self-rated health and education). Both correlations are significant at $1 \%$ level.
} 
usefulness as a risk-class, the need for blood tests to verify smoker status makes it less palatable than the set of readily-measurable factors already identified in Model 3.

Table 1 reports the parameter $\gamma$, which controls the shape of the baseline hazard. The value of $\gamma$ varies depending on the model specifications, but the key is that $\gamma$ is a positive value indicating monotone hazard functions that increase exponentially with time. ${ }^{41}$ Because it has been verified in Section 3 that the male and female hazards have the same shape, a unisex $\gamma$ will be applied in the subsequent pricing simulations. A related issue is then whether $\gamma$ differs significantly for the younger versus older respondents, since there is a maximum possible age gap of 12 years. To test for this age-covariates interaction, I divide the respondents into two groups: ages 50-57 (two-thirds of the sample) and ages 58-62. The number of deaths in both groups is pretty similar. Results are shown in Appendix Table 2.

Slight differences emerge: for the older group, the age covariate is not statistically significant $(\mathrm{HR}=1.04,95 \% \mathrm{CI}=0.97,1.12, \mathrm{p}>.10),{ }^{42}$ and the negative effect of chronic diseases and low BMI on mortality seems less intense. ${ }^{43}$ For instance, an older person with cancer faces 1.7 times the mortality risk of someone without (compared to 2.3 for a younger counterpart). One possible explanation is that at advanced ages, physical conditions become less predictive of mortality (everyone eventually becomes frail and disease-ridden), whereas mental health emerges as a more significant determinant. Although the dataset we use precludes our validating this surmise, it appears that cognitive score and years of education (proxies of mental ability) predict mortality slightly better for the older group. But overall, there are no substantial differences in the hazard ratios or $\gamma$ between the two age groups; thus, I proceed with the combined sample.

\subsection{Improved Predictive Ability from Risk-class Pricing}

One of the objectives of this paper is to explore the possible impact of pricing annuity benefits using additional risk-classes vis-à-vis existing pricing factors (age and sex). To do so, I

\footnotetext{
${ }^{41}$ This is consistent with Figure 2.

42 The magnitude of the odds ratio, however, is similar to that for the younger group.

${ }^{43}$ Our results show that the hazard ratios for six of the eight chronic disease conditions are lower for the older group. This is consistent with results in Lee et al. (2008). Using HRS data, that study finds that as age increases, the ability of chronic conditions to predict mortality declines rapidly. Chronic conditions are stronger predictors of death for younger participants (aged 50-59 years) than for older participants.
} 
compare the values of adjusted $R^{2}$ across the four models. ${ }^{44}$ Controlling only for age and sex in "M1" explain about 6.7\% (SE 0.0093) of variance in mortality outcomes. In contrast, "M2" and "M3" have adjusted $R^{2}$ values of 29.7\% (SE 0.0139) and 30.6\% (SE 0.0138) respectively. In other words, implementing the 12 to 18 additional risk-classes will allow an insurer to explain about five times more variation in mortality, suggesting that much prognostic information is carried by the additional variables.

To assess the relative contributions of individual predictors, I remove variables from "M3" one at a time - in the order that reduced $R^{2}$ the least at each step. For the given sample, diabetes is the most important predictor of mortality, followed (in this order) by lung disease, heart disease, sex, age, marital status, high blood, cancer, own schooling, BMI, psychiatric condition, cognition, birth region, stroke, father's longevity, race, mother's education, father's education, arthritis, and mother's longevity. This ranking suggests that prior health history (other than arthritis) and demographic variables (particularly age, sex, and marital status) are important predictors of mortality for people close to retirement. Objectively-measured variables such as BMI and cognition also rank moderately well, which lends weight to their use in annuity pricing. Race does not rank highly on this list, probably because it serves as a proxy for SES, which in this case may have been largely captured by the education variable. Parental education is ranked low, which is not surprising since the mortality of older adults may no longer be strongly associated with parental SES.

In what follows, the ten best-ranked additional risk-classes are combined with age and sex to form a "risk-class pricing" scheme. ${ }^{45}$ This new model specification with a total of 12 variables has an adjusted $R^{2}$ value of $29.7 \%$ (SE 0.0137). It is posited that this "risk-class pricing" scheme which is richer in information will allow insurers to derive more accurate mortality predictions than the "age-sex pricing" scheme. This paper proposes a novel approach to make this assessment by comparing age-at-death prediction intervals. To the best of my knowledge, this procedure has not been demonstrated in previous population-based studies of mortality.

\footnotetext{
${ }^{44}$ The values of adjusted $R^{2}$ are found at the bottom of Table 1 . In the context of censored survival data, the adjusted $R^{2}$ measures how much of the variation in outcome in a PH model is accounted for through the prognostic index $(x \beta)$, adjusting for the dimension of the model. See Royston (2006) for details. The Harrell's $C$ and Somers' $D$ statistics for Cox PH models are not suitable for use with our weighted analysis.

${ }^{45}$ Results (not presented) show that this ranking using adjusted $\mathrm{R}^{2}$ is consistent with other variable selection methods. Stepwise and forward selection procedures both confirm that parental education, mother's longevity, arthritis, and birth region are the least significant variables. A slight difference is that the forward selection method ranks 'stroke' as one of the top 12 factors in lieu of 'own schooling'.
} 
Studying age-at-death intervals is of interest since insurers will want to pinpoint, as accurately as possible, how long annuity payouts need to be made.

Age-at-death probability density functions are derived from post-PH regression estimates. These density functions show the relative likelihood of the individual dying at each point in time, i.e. the probability of dying before month $k+1$ given survival to month $k$. Formally, let $(d)$ denote the age of a retiree who purchases an individual life annuity at time 0 . A discrete random variable associated with her future lifetime is $K(d)$ where discrete time periods are measured in months. ${ }^{46}$ The survival function and density function of $K(d)$ are, respectively:

$S(k)=\operatorname{Pr}[K(d)>k]={ }_{k} p_{d}, \quad d \geq 50, k=0,1,2, \ldots$,

$\operatorname{Pr}[K(d)=k]={ }_{k} p_{d}-{ }_{k+1} p_{d}={ }_{k} p_{d}{ }_{1} q_{d+k}$,

where ${ }_{k} p_{d}$ is the probability that $(d)$ will attain age $d+k$ (or so-called cumulative survival probability), and ${ }_{1} q_{d+k}$ is the one-period mortality rate at age $d+k$. The constraint of $d \geq 50$ is consistent with the minimum age of the given sample. The assumed terminal age that an individual can live up to is 120. Essentially, Equation (4) is the discrete-form equivalent of Equation (3). Fitted estimates of the survival function are derived for price simulations discussed in the next section. The focus here is the fitted estimates of the density function derived from Equation (5).

It is also useful to introduce the notion of a 'risk-group'. Individuals who share a common density function are called a risk-group. In the context of annuities, a risk-group with a longer lifespan is 'riskier' than another. Given that the sample consists of a number of riskgroups, the objective here is to analyze how the density functions estimated under the two different annuity pricing schemes will differ, in the presence of such heterogeneity. In particular, consider four distinct risk-groups profiled as follows:

(i) High longevity-risk: 55-year-old female, no disease history, slightly overweight, married, completed high school (HS-educated), above-average cognition.

\footnotetext{
${ }^{46}$ In actuarial terminology, this is called the curtate-future-lifetime of $(d)$. See Bowers (1997).
} 
(ii) Average risk: 55-year-old female, no disease history, normal weight but is not married, not HS-educated, average cognition. (Note that this mortality profile is obtained by setting all 10 additional risk variables at their reference categories.)

(iii) Low risk: 55-year-old female, history of cancer, underweight, is not married, not HS-educated, below-average cognition.

(iv) Very low risk: 58-year-old male, overweight, has heart disease, high blood and psychiatric illness, not married, not HS-educated, below-average cognition.

Figure 3 plots the density functions for each risk-group. For the first three subgroups, the density curves estimated from age-sex pricing alone (dotted lines) are identical; the benchmark is the density function for an average 55-year old female. In contrast, estimates obtained from "risk-class pricing" (solid lines) vary significantly across the three risk-groups; the subgroup with longer longevity is expected to die later than others. Overall, this enables readers to visualize exactly how incorporating more risk-classes improves predictive power: insurers are not only able to distinguish across risk profiles, but also obtain tighter age-at-death prediction intervals (narrower distributions). In addition, the solid line functions reveal higher peaks implying that the most probable ages of death are associated with greater weight (higher probability levels).

Figure 3 here

The bottom-right plot in the Figure illustrates the density curves for a very low-longevity risk-group; here we characterize this as an older male with a history of several diseases. In such cases, substantial differences in mortality predictions can emerge: for instance, "risk-class

pricing" predicts a most probable age-at-death at 64 , whereas "age-sex pricing" yields a prediction of age 83. Having selected suitable risk-classes and demonstrated how incorporating these additional factors will lead to improved age-at-death predictions, the next step is to analyze how implementing these risk-classes affects the financial value of annuities for different demographic groups.

\section{$4 \quad$ Price Simulations on a Purely Financial Basis}


This section briefly describes the actuarial valuation approach for life annuities and presents simulation results for a hypothetical cohort of 65 -year-old potential annuity buyers. ${ }^{47}$ It should be noted that this pool of individuals is not related in any way to the earlier sample of HRS respondents. I first simulate the annuity benefit flows accruing to a variety of risk-groups, and then simulate the annuity premiums that would be charged under different actuarially fair pricing schemes. These results are combined to obtain the money's worth ratio for various riskgroups under alternative pricing schemes assuming no loading.

\subsection{Benefit Flows to Annuitants}

Consider a standard, nominal, whole life annuity that pays $\$ 1$ per month as long as the annuitant is alive. The first payout starts at time $t=0$ when the annuity is purchased. This is the only product available to individuals in this simulation. The benefits to annuity purchasers in the same risk-group can be quantified as follows:

$E P D V=\sum_{t=0}^{\infty} \$ 1 \cdot v^{t} \cdot{ }_{t} p_{d}^{\text {group }}$

where EPDV refers to the expected present discounted value of future annuity payouts. In addition, $v$ is the discount factor, ${ }_{t} p_{d}^{\text {group }}$ is the set of cumulative survival probabilities for a risk-group, $d$ is the age at which the annuity is purchased, and $t$ is time expressed in months. In actuarial terminology, the EPDV is called the actuarial present value of a life annuity and the upper bound of the summation is set to infinity by convention. Equation (6) captures the present value of the series of annuity benefits that an annuitant in a particular risk-group can expect to receive over her remaining lifetime.

Risk-groups can be defined using any combination of risk factors. For instance, a broadly-defined risk-group might be 'age 65, females'; their set of ${ }_{t} p_{d}^{\text {group }}$ can be estimated from a $\mathrm{PH}$ regression that controls only for age and sex. ${ }^{48}$ Another example of a risk-group

\footnotetext{
${ }^{47}$ Earlier studies that perform annuity value simulations have similarly focused on a cohort of same-age annuitants. For instance, Brown (2003) uses a cohort of 67-year-olds. Mitchell et al. (1999) and Turra and Mitchell (2008) focus on a cohort of 65-year-olds. Age 65 is selected here because it is closer to the expected retirement age of the sample of HRS respondents (mean=63.5, $\mathrm{SD}=3.65$ ) used in the earlier regression analyses.

${ }^{48}$ Robustness checks are performed to determine if the fitted estimates of ${ }_{t} p_{d}$ are reflective of rates reported in actuarial lifetables. Results (not presented) show that the fitted cumulative survival estimates generated from the PH regression controlling only for age and sex (i.e. Model 1) are close to the survival probabilities constructed from the Social Security Administration (SSA) birth cohort tables. The 1930 and 1940 sex-specific SSA cohort tables are
} 
would be 'married, high-school educated, age 65, females' - and any female with these four characteristics would be in the group (even though some would be suffering from a disease and some would not). Their set of ${ }_{t} p_{d}^{\text {group }}$ is estimated from a PH regression that controls for age, sex, education, and marital status. In the simulations that follow, a nominal annual interest rate of $6 \%$ is assumed (this rate reflects the average 30-year Treasury bond yield for the last 20 years) and I also present sensitivity analysis using an alternative value of $4 \% .{ }^{49}$ Further, the assumed terminal age of survival is $120 .^{50}$

Table 2 presents the simulated expected annuity benefits (or EPDV) for a variety of riskgroups. The row in the middle shows that a 65-year-old annuity purchaser, on average, can expect to receive $\$ 126$ in annuity benefits. If the fact that females live longer than males is accounted for, then plugging sex-specific survival probabilities into Equation (6) reveals that the estimated EPDV for females is actually \$16 higher than that for males. If we further account for the education level of the annuitant, then the EPDV of high-school educated groups will be larger than that of non-high-school educated groups. The top and bottom rows of the Table draws a contrast between a very long-lived group profiled by 'females with no high blood, married, and high-school-educated' (EPDV \$152) and a very short-lived group profiled by 'males with high blood, unmarried, and low-educated' (EPDV \$81). In essence, the Table reflects a spectrum of longevity profiles in a heterogeneous cohort, although one can easily imagine other forms of representative profiles. ${ }^{51}$

Table 2 here

\footnotetext{
used since the HRS sample respondents are born 1931-1941, and are sourced from www.ssa.gov/OACT/NOTES/as120/LifeTables_Tbl 7.html.

${ }^{49}$ The average 30-year Treasury bond yield from 1988 to 2010 is $6.3 \%$ (the bond was discontinued between 2003 and 2005 but re-introduced in 2006). In recent years, yields have been falling. As at end 2010, the 30-year Treasury bond yield is 4.25\%. Source: Federal Reserve Statistical Release (www.federalreserve.gov/releases/h15/data.htm). Prior studies (e.g. Mitchell et al. 1999) have similarly used the 30-year Treasury bond yield to proxy a flat nominal term structure. The discount factor is computed using $v=1 /(1+i)$, where $i$ denotes the nominal interest rate. It is also assumed that the insurer always earns exactly this rate on the assets backing the annuity, and so any profit or loss stems solely from annuity pricing simulations and not from reinvestment risk.

${ }^{50}$ A terminal age (denoted $w$ ) of 120 is appropriate for two reasons. First, it has been used as the limiting age in official cohort lifetables from the U.S. Social Security Administration. Second, it appears to be a reasonable choice for the sample here since the maximum death ages observed for deceased parents are 105 (father), and 110 (mother) suggesting it is plausible that HRS respondents can potentially live to 120. In Equation (6), the upper bound of the summation can thus be alternatively expressed as $(w-d) \times 12$.

${ }^{51}$ For example, 'females with lung disease, underweight, and poor cognition' will also fit the profile of a very shortlived group.
} 


\subsection{Premiums Charged by Insurers}

How premiums are set depends on the prevailing pricing scheme in the market. To simplify the analysis, zero-loading is assumed so the insurer is assumed to set premiums just sufficient to break-even for each benchmark group that it prices. ${ }^{52}$ Table 3 illustrates the dollar premiums charged to the hypothetical pool of age 65 individuals under different pricing schemes for a $\$ 1 /$ month life annuity. In an 'age-only' pricing scheme, the insurer will set a price based on the average survival probabilities of 65-year-olds. All annuity buyers will be charged the same premium of $\$ 126$. Under 'age-sex' pricing, the insurer no longer charges a single price but now has to differentiate between the sexes. The insurer uses the average survival probabilities of 65year-old females to derive a premium of $\$ 134$, and all female annuity purchasers (whether they are married or unmarried, with disease or without) must pay $\$ 134$. Because of their lower average survival probabilities, males are charged a lower premium of $\$ 117$.

\section{Table 3 here}

Row 3 of the Table shows that if an 'age-sex-education' scheme is adopted instead, there will be a total of four distinct prices after accounting for the different permutations among the pricing factors; high-school educated females paying the highest premium of $\$ 145$. It is also important to note from this analysis that risk-groups become more narrowly-defined when the pricing scheme becomes more detailed; for example, it is not possible to compute a premium for a risk-group of 65-year old females under 'age-sex-education' pricing.

Risk-based pricing essentially allows insurers to price-discriminate more finely across different risk profiles. As pricing schemes incorporate more details, the schedule of possible premiums offered by an insurer grows exponentially. The Table shows that using six rating classes will result in 32 distinct prices ranging from \$82-160. If all the top 12 pricing factors are used, then there are possibly more than 4,000 distinct premiums to account for the various permutations of 65-year old annuitants. All the results in the Table assume zero-loads. Loads can be factored into the analysis, for example, by assuming that they form a fixed percentage of the premium. If loads are say $10 \%$, then all simulated premiums simply decrease by $10 \%$, in which case, the relative prices charged to different buyers are unaffected.

\footnotetext{
${ }^{52}$ Insurers typically add loadings to the insurance products they sell to cover administrative costs and to incorporate some profit margin. Such loadings are borne by the consumers.
} 


\subsection{Money's Worth Ratios Results}

To assess the financial value of annuities accruing to different demographic groups, a metric called the "money's worth ratio (MWR)" is employed. The MWR measures the financial value of an annuity investment to the individual, and it is simply the ratio of the EPDV over the annuity premium paid. If the MWR is less than 1, then the individual is expected to receive less back in payouts than what she paid. If she decides to buy the annuity, she would anticipate receiving a negative expected transfer. If MWR is greater than 1, then the annuitant would anticipate receiving a positive expected transfer.

Table 4A presents the MWR values for different demographic groups under a variety of pricing schemes. These values are derived using the simulated EPDV and premium estimates discussed earlier. It is important to note that these are the values available to individuals if they should decide to buy the annuities; thus this analysis does not require the assumption that all individuals must annuitize. The key takeaway from this Table is that shorter-lived annuity purchasers will be made financially better off (and the longer-lived made worse off) when more detailed pricing schemes are implemented. This is evidenced by focusing on the 'top' and 'bottom' risk-groups in the Table which represents longer-lived and shorter-lived profiles

respectively. Under age-sex pricing, the MWR for the shorter-lived group is 0.693. MWR increases substantially to 0.893 when additional factors such as education and marital status are used - this is about a $29 \%$ increase in financial value for every dollar they invest in annuities. This is because when pricing incorporates more personal characteristics, shorter-lived individuals enjoy lower premiums that reflect their high mortality attributes. In contrast, the longer-lived are charged higher premiums causing their MWR to decline. The longer-lived riskgroup has a MWR of 1.204 under 'age-only' pricing (scheme S1) but only a MWR of 1.047 under the more detailed pricing scheme S4.

\section{Table 4 here}

An interesting observation is that the incremental gains achieved by the shorter-lived exceed the incremental losses experienced by the longer-lived group. Moving progressively from scheme S2 to S4, the Table shows 13 to $15 \%$ gains in MWR for the shorter-lived. These gains are substantial as compared to the modest declines of 3 to $5 \%$ for the longer-lived. This suggests that the effect of adopting more factors in annuity pricing in a heterogeneous population of annuity purchasers is likely to be uneven; longer-lived groups will be made just slightly worse 
off but shorter-lived groups will be disproportionately much better off. The intuition here is that it is generally harder to increase one's survival probability than to worsen it. Hazard ratios reveal that the combined longevity advantage of being married, HS-educated, female, and without high blood, decreases the risk of death by only $50 \%$ vis-à-vis the baseline individual. Yet, having the exact opposite attributes (all else equal) increases the mortality risk of an individual by $313 \% .^{53}$ In other words, the survival curve of the longer-lived will lie just slightly above that of the baseline individual but the survival curve of the shorter-lived will lie far below the baseline curve. This disparity in survival estimates results in the premium falling more for the shorterlived than it rising for the longer-lived when a pricing factor is added.

In sum, the MWR analysis suggests two important reasons why more detailed pricing may help reduce adverse selection in annuity markets. First, shorter-lived groups will be induced to buy annuities. Where they may have stayed out of the annuity market previously under simpler pricing, they may now decide to annuitize given decent MWR values of 0.8 to 0.9. Moreover, as pricing schemes become progressively more detailed, the incremental gains in MWR (13-15\%) accruing to these shorter-lived groups are substantial. Second, longer-lived groups still have an incentive to annuitize even when more detailed pricing is implemented. This is because the penalty that these groups bear through higher premiums results in only modest financial losses of about 3-5\%; moreover, they can still expect to enjoy positive expected transfers from annuitization as MWR $>1$. Sensitivity analysis reveals that these results remain robust under a lower interest rate assumption (see Table 4B).

While the MWR is a useful metric, it ignores the insurance value that individuals may derive from the elimination of longevity risk. The next section describes a utility-based model and quantifies the utility gains accruing to different demographic groups under the assumption of risk aversion. It assesses whether shorter-lived groups may obtain utility gains from more detailed pricing schemes, and if so, whether they are as substantial as the financial gains.

\footnotetext{
53 The computations are based on the hazard ratios in Column M2, Table 1. Death hazards are multiplicatively proportional. Assuming all other factors are set at their reference categories, a married, HS-educated, female without high blood has a mortality risk of $0.69 * 0.73 * 1 * 1=0.504$ whereas an unmarried, non-HS-educated, male who everhad high blood has a mortality risk of $1 * 1 * 1.92 * 1.63=3.13$.
} 


\section{Price Simulations on a Utility-Adjusted Basis}

This section primarily builds on the work by Brown (2001, 2003) and Mitchell et al. (1999) ${ }^{54}$ In particular, I adopt the approach developed in these studies to quantify the welfare gains of annuitization to an individual using a metric called the "annuity equivalent wealth (AEW)". Unlikely the MWR, the AEW is a utility-based measure of annuity valuation and it has been shown in prior studies that individuals may find an annuity to be welfare-enhancing even if $\mathrm{MWR}<1$.

Closest to this present paper, Brown (2003) studies the utility-adjusted value of annuitization for a cohort of 67-year-olds of heterogeneous mortality under two pricing scenarios. Mortality is differentiated using sex, education, and race. ${ }^{55}$ One pricing scenario examined is unisex uniform pricing (which corresponds to age-only pricing) and the other scenario is actuarially fair pricing for each and every separate demographic group. This present paper aims to extend the empirical analysis on two fronts: first, I consider intermediate pricing scenarios that lie between the two markers. Thus the pricing scheme prevailing at any point in time may be more than actuarially fair for some demographic groups and less than actuarially fair for other groups. ${ }^{56}$ This is perhaps a better reflection of reality since insurers are likely to adopt additional risk-classes progressively as depicted by the intermediate pricing scenarios. Second, I examine a more diverse set of demographic groups. In particular, I differentiate mortality along more demographic lines, including education, marital status, and disease condition, which serves to broaden the analysis in useful ways. ${ }^{57}$ In what follows, I describe the multi-period, stochastic life-cycle model used to evaluate the insurance value of an annuity under uncertain lifetimes and simulate AEW results for the hypothetical cohort of 65-year-olds.

\subsection{Analytical Framework for AEW}

\footnotetext{
${ }^{54}$ I am especially grateful to Jeffery R. Brown for sharing his optimization code originating from Brown (2001).

55 According to Brown (2003), education is selected in because it is a reasonable proxy for lifetime resources and is also a predetermined variable for most retired individuals. Race is selected because it is directly relevant to the politics of the Social Security debate in the U.S. This is consistent with the study's objective of assessing the utility implications of mandating annuitization in an environment of heterogeneous mortality.

${ }^{56}$ The pricing scheme will be actuarially fair for groups which are identified as benchmarks in that particular scheme. These benchmark groups have been identified in Table 3 and have MWR values of 1.000 in Table 4 .

${ }^{57}$ Differentiating along more demographic lines increases the mortality heterogeneity between the 'top' and 'bottom' risk-groups, thus leading to a larger observed dispersion in MWR and AEW values. In addition, the choice of factors matters; selecting factors that are less correlated will create greater mortality heterogeneity between the risk-groups analyzed.
} 
At the posited retirement age of 65 , the individual decides how much of her initial wealth to annuitize. The retiree is assumed to be solving an expected utility maximization problem. Formally, let $U\left(C_{t}\right)$ represent the one-period utility function defined over real consumption, ${ }_{t} p_{a}$ is the probability that an individual survives to period $t$ ( $t$ is expressed in years), $\rho$ the time preference rate, and $\omega$ the terminal age (assume 120). Then, assuming additive separability over time, the value function $V_{t}\left(W_{t}\right)$ is defined as:

$V_{t}\left(W_{t}\right)=\operatorname{Max}_{\left\{C_{t}\right\}}\left[\sum_{t=1}^{\omega-65+1} \frac{{ }_{t} p_{65} \cdot U\left(C_{t}\right)}{(1+\rho)^{t}}\right]$,

subject to the following constraints:

(i) $W_{0}$ is given,

(ii) $W_{t} \geq 0, \forall t$,

(iii) $W_{t+1}=\left(W_{t}-C_{t}+A_{t}\right)(1+r)$.

In this set of constraints, $W_{t}$ is non-annuitized wealth in period $t, C_{t}$ is consumption in period $t$, $A_{t}$ is the annuity income she receives in period $t$ if she had purchased an annuity, and $r$ is the real interest rate. There is no expectation operator because the survival probabilities have been explicitly accounted for, and there are no other sources of uncertainty in this problem. In addition, as in prior studies, I assume no bequests, no loadings, and no taxes in this setup. This value function at time $t$ is the present discounted value of expected utility evaluate along the optimal path. Knowing the optimal decision in period $t$ allows one to find the optimal decision that maximizes the value function in period $t-1$. The problem is thus solved numerically using backward recursion from the final period, and may be expressed by the following recursive Bellman equation:

$\operatorname{Max}_{\left\{C_{t}\right\}} V_{t}\left(W_{t}\right)=\operatorname{Max}_{\left\{C_{t}\right\}} U\left(C_{t}\right)+\frac{{ }_{1} p_{t+1}}{(1+\rho)} V_{t+1}\left(W_{t+1}\right)$,

where ${ }_{1} p_{t+1}$ is the one-period probability of surviving in period $t+1$.

Consistent with prior studies, I apply standard methods of discretizing the wealth space, and adopt the standard assumption that individuals exhibit constant relative risk aversion 
(CRRA) ${ }^{58}$ The CRRA utility allows the simulation results to be invariant to the level of wealth possessed by the individuals in the different demographic groups at retirement. In other words, the value of annuitization derived by each demographic group will be unaffected by the differences in wealth levels across groups. The CRRA utility structure is:

$U\left(C_{t}\right)=\frac{C_{t}^{1-\gamma}}{1-\gamma}$

where $\gamma$ is the coefficient of relative risk aversion. More risk-averse individuals will value annuities more highly than less risk-averse individuals. Consistent with earlier studies such as Hubbard et al. (1995), a $\gamma$ parameter of 3 is used for the main analysis. Sensitivity analysis using an alternative value of $\gamma=1$ is also presented since a risk aversion of 1 corresponds to $\log$ utility, and has been found to be the average risk aversion in prior studies on consumption (e.g. Laibson et al. 1998).

The analysis proceeds with a counterfactual exercise using two scenarios. Assume that an individual has initial financial wealth $W^{*}$. In the first scenario, individuals have full access to an annuity market where single-life, fixed-payout, nominal payout annuities are sold. Assume that the individual annuitizes all resources she has, i.e. $W_{0}=0$. The annual income she obtains from the annuity $\left(A_{t}\right)$ is determined by the pricing scheme used by the insurer. For the special case in which the annuity is actuarially-fair for the individual, $A_{t}$ is determined by:

$A_{t}=\frac{W^{*}}{\sum_{t=1}^{\omega-65+1} \frac{{ }_{t} p_{65}}{(1+r)^{t}(1+\pi)^{t}}}$

where $r$ is the real interest rate, and $\pi$ is the inflation rate. The maximum utility $V^{*}$ the individual attains in this first scenario can be found by solving the maximization problem subject to the constraints in Equation (2).

Turning to the second scenario, assume now that no annuity market is available. That is, $W_{0}=W^{*}$ and $A_{t}=0, \forall t$. I solve the maximization problem again and find the amount of additional wealth, $\Delta W$, which must be given to the individual (in the absence of annuities) so

\footnotetext{
${ }^{58}$ See Turra and Mitchell (2008), Brown (2003, 2001), and Mitchell et al. (1999).
} 
that she can achieve the utility level $V^{*}$. Given this setup, the annuity equivalent wealth (AEW) is thus defined as:

$A E W=\frac{W^{*}+\Delta W}{W^{*}}$.

In essence, the utility-based measure of AEW is similar to the Equivalent Variation measure in applied welfare analysis. Specifically, it quantifies how much an individual's wealth needs to be multiplied by (in a scenario without annuities) in order to generate the same utility level as in the scenario where annuities are available. In a multi-period life-cycle model with risk-averse individuals, the AEW is typically a number greater than unity since the option of annuitization is valuable. Following Brown (2003), the simulations here assume $\rho=r=\pi=3 \%$. ${ }^{59}$ Also, simulations only focus on annuity contracts that pay fixed, nominal benefit streams. ${ }^{60}$

\subsection{Annuity Equivalent Wealth Results}

Annuity prices (defined here as the annual annuity income for a given premium ${ }^{61}$ ) are constructed by replacing the ${ }_{t} p_{65}$ in Equation (11) with the appropriate set of survival probabilities. For example, if annuities are priced based on age and sex only, then the annuity income for a married, or unmarried, 65-year old female is found using the average survival probabilities of 65-year old females. It is important to note that the mortality rates used as input to determine pricing are only averages and significant dispersion in mortality will exist among say, the group of 65-year old females. As such, annuities that are age-sex priced in an actuarially-fair manner for 65-year old females will be more than actuarially-fair for a married

\footnotetext{
${ }^{59}$ Some important parameters adopted in this present paper are different from Brown (2003), for instance, mortality inputs, age of annuitization, and limiting age. While Brown (2003) considers mortality differentiated by age, sex, race, and education, this present paper differentiates risk-groups by age, sex, education, marital status, and disease conditions. The selection of risk-classes is important since correlations among the risk-classes affect the amount of mortality heterogeneity across the various risk-groups, and in turn affect the dispersion in AEW results.

${ }^{60}$ The focus of this present paper is on the dispersion in annuity equivalent wealth ensuing across different pricing schemes, thus only one annuity type is illustrated. Readers who are interested in how the dispersion in AEW varies across annuity types can refer to Brown (2003).

${ }^{61}$ Annuity pricing can be expressed in two ways. The first is that the insurer determines the annuity premium as in the MWR analysis. This applies to a fixed-payout annuity (e.g. annuity pays $\$ 500 /$ month for life). The second is that the insurer determines the quantum of payout for a given premium invested. This applies when the annuitant decides to invest, say $\$ 100,000$, in an annuity. In both cases, the insurer sets the 'price' and annuitant is the price-taker.
} 
65-year old female with no diseases, and less than actuarially-fair for an unmarried, lowcognition 65-year old female.

Table 5 reports the annual annuity income for a $\$ 100,000$ policy under various pricing schemes. If individual-life annuities are age-sex priced, a 65-year old male will receive \$10,898 per year, while a female will receive a lower annual income of $\$ 9,492$ due to her longer life expectancy. Under pricing scheme S3, lowly-educated individuals will benefit from an increase in annuity income. In particular, the Table shows that lowly-educated males now receive \$12,344 in annual income as compared to $\$ 10,898$ under scheme $\mathrm{S} 2$. In contrast, better educated individuals experience a decline in annuity income. A high school-educated female now receives only $\$ 9,036$ (compare $\$ 9,492$ under $\mathrm{S} 2$ ) since her premium educational level is now factored into the annuity pricing. In the very detailed pricing scheme S4, an unmarried, lowly-educated male will receive $\$ 5,527$ more annually than a married high school-educated female for the same given annuity premium of $\$ 100,000$.

\section{Table 5 here}

Table 6A presents the annuity equivalent wealth for different demographic groups under different pricing schemes. Results show that the utility gains from annuitization are substantial for both genders under the age-sex pricing scheme used in the U.S. annuity market today. This finding is consistent with previous empirical analyses (e.g. Brown 2003; Mitchell et al. 1999). In particular, females - on average - have an AEW of 1.474, meaning that they will be indifferent between $\$ 1$ of annuitized wealth and $\$ 1.47$ of non-annuitized wealth. Compared to average females, women with longevity-enhancing attributes such as being married, or being highlyeducated, enjoy even higher AEW values (1.482 to 1.495) because they have higher survival probabilities and are thus more likely to be alive to consume the annuity.

\section{Table 6 here}

Average males have an AEW of 1.644; this is comparable to Brown (2003)'s figure of 1.633 under age-sex pricing. The Table also shows that unmarried or lowly-educated males have lower AEW values than the average male. These risk-groups find annuities less valuable since they are less likely to survive to consume the annuity. Nonetheless, even those with very poor mortality prospects benefit from the annuitization option. For example, even the 'bottom' riskgroup of unmarried, lowly-educated males with high blood disease has an AEW of 1.445. 
As with the money's worth analysis, AEW results here show that shorter-lived groups find annuities more valuable as pricing becomes more detailed while longer-lived groups find annuities less valuable. The 'bottom' group experiences a 30\% increase in utility moving from age-sex pricing to scheme S4 and it should be noted that these utility gains are achieved by adding just a couple of pricing factors. In contrast, the 'top' group experiences a modest $8 \%$ loss in utility but still obtains a decent AEW of about 1.4 under the detailed pricing schemes. Sensitivity analysis shows that the AEW figures are generally smaller under log utility, i.e. $\gamma=1$ (see Table 6B). This is because individuals with lower degree of risk aversion value annuities less than those who are more risk-averse. Nonetheless, the finding that high-mortality-risk groups benefit the most from annuitization when annuity pricing becomes more detailed remains robust.

\section{Discussion and Conclusion}

Annuities provide valuable longevity insurance to individuals with uncertain lifetimes. The aging of the boomer generation in the U.S. and the global advent of individual retirement accounts will likely increase the demand for annuities. Yet in the U.S. as well as in many other developed countries, prices of most standard retail annuities do not reflect buyers' personal characteristics other than age and sex. Some impediments to annuity underwriting may be costs and thin annuity markets. It may also be that insurers think underwriting is not profitable, which would be true if mortality differentials were not substantial. Nonetheless, the results in this paper suggest that mortality differentials are in fact substantial. Explained variation in mortality doubles from $6.7 \%$ to $12.6 \%$ just by using education and marital status, in addition to age and sex. Adjusted $\mathrm{R}^{2}$ increases further increases to $29.7 \%$ when the ten best-ranked factors are used along with age and sex. Moreover, these factors are readily-measurable and therefore not costly to collect.

A main contribution of this paper has been to show that more detailed pricing may reduce adverse selection in annuity markets. This can be attributed to two effects that occur when more pricing factors are implemented. First, shorter-lived groups may be sufficiently induced to buy annuities. Where they may have stayed out of the market previously, they may now decide to annuitize since they are able to obtain decent MWR values of 0.8 to 0.9 . Adding just one or two risk factors to age-sex pricing results in substantial financial gains (13-15\%) for these groups. In 
relation, the AEW analysis shows that shorter-lived groups can achieve attractive utility gains of about $30 \%$ when more detailed pricing is implemented. The second effect is that longer-lived groups will still be incentivized to stay in the annuity market. Although more detailed pricing schemes results in higher premiums for the longer-lived groups, they are not severely penalized. These groups experience only modest financial and utility losses of about 3 to $5 \%$. With the shorter-lived groups entering the annuity market and longer-lived continuing to consume annuities, annuity markets are likely to grow which in turn reduces adverse selection.

Overall, these findings lend support to the movement towards risk-based annuity pricing for standard retail products, which has already begun in the U.K. and may possibly spread to other countries. On the other hand, it implies that the European Union's recent elimination of the use of sex in insurance pricing, including annuities, represents a step backwards for the ongoing efforts towards greater risk-classification. Reducing the number of risk-classes will bring about greater dispersion in annuity values between the shorter and longer-lived risk-groups, which has possible redistributive implications in the event that all individuals purchase annuities, for example under a mandate. ${ }^{62}$ One limitation of this study is that the analysis is performed for a hypothetical cohort of 65-year-old individuals, without employing weights relevant to the HRS sample used for regression analysis. Future research can extend the analysis to the nationally representative sample of HRS respondents. This will allow me to better model selection effects under various pricing schemes and also quantify the impact of more detailed pricing on adverse selection for a nationally representative mix of risk classes in the population at large.

\footnotetext{
${ }^{62}$ Annuitization mandates have been actively considered by policymakers as a longevity risk management tool. For example, annuitization was compulsory in U.K. defined contributions plans for many years until recently. Singapore will implement an annuitization mandate in its national provident fund by 2013 (Fong et al. 2011). Mandating life annuity purchase may be one approach to limiting adverse selection in annuity markets, provided that appropriate regulation is in place (Bateman et al. 2001).
} 


\section{References}

Abel, A., and M. Warshawsky, 1988, Specification of the Joy of Giving: Insights from Altruism, Review of Economics and Statistics, 70(1): 145-149.

Banking Times, 2008, NU Increases Risk Factors in Annuity Pricing, June 17. www.bankingtimes.co.uk/17062008-nu-increases-risk-factors-in-annuity-pricing/, viewed on $10 / 31 / 2010$.

Bateman, H., G. Kingston, and J.R. Piggott, 2001, Forced Saving: Mandating Private Retirement Incomes, Cambridge University Press.

Batty M., A. Tripathi, A. Kroll, C. Wu, D. Moore, C. Stehno, L. Lau, J. Guszcza, and M. Katcher, 2010, Predictive Modeling for Life Insurance, Deloitte Consulting LLP, April.

Bestwire, 2010, Towers Watson Finds Growth in U.K. Enhanced Annuity Market, September 9. http://insurancenewsnet.com/article.aspx?id=224602\&type=annuity, viewed on 10/31/2010.

Bongaarts J., and G. Feeney, 2002, How Long Do We Live?, Population And Development Review 28(1): 13-29.

Bowers, N., H. Gerber, J. Hickman, D. Jones, and C. Nesbitt, 1997, Actuarial Mathematics, Society of Actuaries, Schaumburg, IL.

Brown, J.R., 2003, Redistribution and Insurance: Mandatory Annuitization with Mortality Heterogeneity, Journal of Risk and Insurance, 70: 17-41.

Brown, J.R., 2002, Differential Mortality and the Value of Individual Account Retirement Annuities, in: M. Feldstein and J. Liebman, eds., The Distributional Aspects of Social Security and Social Security Reform, University of Chicago Press for NBER, Chicago, 401446.

Brown, J.R., 2001, Private Pensions, Mortality Risk, and the Decision to Annuitize, Journal of Public Economics, 82(1): 29-62.

Brown, R.L., and P. Scahill, 2010, Issues in the Issuance of Enhanced Annuities, Social and Economic Dimensions of an Aging Population Program: Research Paper No. 265, McMaster University.

Brown, R.L., and J. McDaid, 2003, Factors Affecting Retirement Mortality, North American Actuarial Journal, 7(2): 24-43.

Cawley, J., and T. Philipson, 1999, An Empirical Examination of Information Barriers to Trade in Insurance, American Economic Review, 89 (4): 827-846.

Chiappori, P. and B. Salanie, 2000, Testing for Asymmetric Information in Insurance Markets, Journal of Political Economy, 108(1): 56-78.

Cleves M., R. Gutierrez, W. Gould, and Y. Marchenko, 2010, An Introduction to Survival Analysis using Stata, $3^{\text {rd }}$ edition, Stata Press, College Station, TX.

Cox, D.R., and E.J. Snell, 1968, A General Definition of Residuals, Journal of the Royal Statistical Society B, 30: 248-275.

Deary, I.J., 2008, Why do Intelligent People Live Longer? Nature, 456: 175-176. 
Deaton, A., and C. Paxson, 2001, Mortality, Education, Income and Inequality among American Cohorts, in: D. Wise, ed., Themes in the Economics of Aging, University of Chicago Press, Chicago, IL.

Dickman, P.W., A. Sloggett, M. Hills, and T. Hakulinen, 2004, Regression Models for Relative Survival, Statistics in Medicine, 23: 51-64

Doyle, S., O.S. Mitchell, and J. Piggott, 2004, Annuity Values in Defined Contribution Retirement Systems: Australia and Singapore Compared, Australian Economic Review, 37(4): 402-416.

Dowd, J.B., and A. Zajacova, 2007, Does the Predictive Power of Self-Rated Health for Subsequent Mortality Risk Vary by Socioeconomic Status in the U.S.? International Journal of Epidemiology, 36(6):1214-21.

Dupre M.E., A.N. Beck, and S.O. Meadows, 2009, Marital Trajectories and Mortality among US Adults, American Journal of Epidemiology, 170(5): 546-555.

Finkelstein, A., and J. Poterba, 2002, Selection Effects in the United Kingdom Individual Annuities Market, Economic Journal, 112: 28-50.

Fisher, G.G., H. Hassan, W.L. Rodgers, and D.R. Weir, 2009, Health and Retirement Study Imputation of Cognitive Functioning Measures: 1992 - 2006, HRS User Guides, University of Michigan, September.

Fong, J.HY., O.S. Mitchell, and B.SK. Koh, 2011, Longevity Risk Management in Singapore's National Pension System, Journal of Risk and Insurance, Forthcoming.

Glymour, M., T. DeFries, I. Kawachi, and M. Avendano, 2008, Spousal Smoking and Incidence of First Stroke, American Journal of Preventive Medicine, 35(3): 245-248.

Gompertz, B., 1825, On the Nature of the Function Expressive of the Law of Mortality, Philosophical Transactions, 27: 513-585.

Hauser, R.M., and A. Palloni, 2010, Why Intelligent People Live Longer, CDE Working Paper, No. 2010-04.

Herzog, A. R., and R.B. Wallace, 1997, Measures of Cognitive Functioning in the AHEAD Study, Journals of Gerontology: Psychological Sciences and Social Sciences, 52B (Special Issue): $37-48$.

Health and Retirement Study (HRS) Tracker, 2009, Data Description and Usage: HRS Tracker 2008 (v1.0), HRS User Guides, University of Michigan, December.

HRS, 2008, Sample Sizes and Response Rates (2002 and beyond), HRS Survey Design Documents, University of Michigan, Fall.

Hubbard, R.G., J. Skinner, and S.P. Zeldes, 1995, Precautionary Saving and Social Insurance, Journal of Political Economy, 103(2):360-399.

Hurd, M., and K. McGarry, 2002, The Predictive Validity of Subjective Probabilities of Survival, Economic Journal, 112(482): 966-985.

Idler, E.L., and R.J. Angel, 1990, Self-Rated Health and Mortality in the NHANES-1 Epidemiologic Follow-up Study, American Journal of Public Health, 80(4): 446-452. 
Idler, E.L., and Y. Benyamini, 1997, Self-Rated Health and Mortality: A Review of TwentySeven Community Studies, Journal of Health and Social Behavior, 38(1): 21-37.

Juster, F.T., and R. Suzman, 1995, An Overview of the Health and Retirement Study, Journal of Human Resources, 30(5): S7-S56.

Kitagawa, E.M., and P.M. Hauser, 1973, Differential Mortality in the United States: A Study in Socioeconomic Epidemiology, Harvard University Press, Cambridge, MA.

Knox, D.M., 2000, The Australian Annuity Market, World Bank Policy Research Working Paper No. 2495, November.

Kotlikoff, L.J., and A. Spivak, 1981, The Family as an Incomplete Annuities Market, Journal of Political Economy, 89(2): 372-391.

Laibson, D., A. Repetto, and J. Tobacman, 1998, Self-Control and Saving for Retirement, Brookings Papers on Economic Activity, 1: 91-172.

Lee, S.J., A.S Go, K. Lindquist, D. Bertenthal, and K.E. Covinsky, 2008, Chronic Conditions and Mortality among the Oldest Old, American Journal of Public Health, 98(7): 1209-14.

Mackenzie, G.A, 2006, Annuity Markets and Pension Reform, Cambridge University Press, Cambridge.

McCarthy, D., and O.S. Mitchell, 2010, International Adverse Selection in Life Insurance and Annuities, in: S. Tuljapurkar, N. Ogawa, and A. Gauthier, eds. Ageing in Advanced Industrial States: Riding the Age Waves, Springer: 119-135.

Mehta, N.K., and V.W. Chang, 2009, Mortality Attributable to Obesity among Middle-Aged Adults in the United States, Demography, 46(4): 851-872.

Mehta, K.M., K. Yaffe, K. Langa, L. Sands, M. Whooley, and K. Covinsky, 2003, Additive Effects of Cognitive Function and Depressive Symptoms on Mortality in Older Community Living Adults, The Journals of Gerontology: Medical Sciences, 58A(5): M461-467.

Mitchell, O.S., J. Poterba, M. Warshawsky, and J.R. Brown, 1999, New Evidence on the Money's Worth of Individual Annuities, American Economic Review, 89(5): 1299-1318.

Orth, B.J., 2008, Approaches for Promoting Voluntary Annuitization, Monograph, presented at the 2008 Retirement 20/20 Conference.

Preston, S.H., P. Heuveline, and M. Guillot, 2001, Demography: Measuring and Modeling Population Processes, Blackwell, Malden, MA.

Preston, S.H., I.T. Elo, I. Rosenwaike, and M. Hill, 1996, African-American Mortality at Older Ages: Results of a Matching Study, Demography, 33(2): 193-209.

RAND Corporation, 2010, RAND HRS Data Documentation: Version J, Rand Center for the Study of Aging, June.

Reuser, M., L. Bonneux, and F. Willekens, 2008, The Burden of Mortality of Obesity at Middle and Old Age is Small. A Life Table Analysis of the US Health and Retirement Survey, European Journal of Epidemiology, 23(9): 601-7. 
Reuters, 2011, U.K. to apply EU insurance gender rule from end 2012, June 30. www.reuters.com/article/2011/06/30/idUKL6E7HU13W20110630?type=companyNews, viewed on $6 / 30 / 2011$.

Rodgers, W.L., M.B. Ofstedal, and A.R. Herzog, 2003, Trends in Scores on Tests of Cognitive Ability in the elderly US Population, 1993 - 2000, The Journal of Gerontology: Social Sciences, 58B(6): S338-S346.

Royston, P., 2006, Explained Variation for Survival Models, The Stata Journal, 6(1): 83-96.

Rusconi, R., 2008, National Annuity Markets: Features and Implications, OECD Working Papers on Insurance and Private Pensions, No. 24, OECD publishing.

Siegel, M.J., E.H. Bradley, and S.V. Kasl, 2003, Self-rated Life Expectancy as a Predictor of Mortality: Evidence from the HRS and AHEAD surveys, Gerontology, 49(4): 265-271.

Sloan, F.A., P. Ayyagari, M. Salm, and D. Grossman, 2010, The Longevity Gap Between Black and White Men in the United States at the Beginning and End of the $20^{\text {th }}$ Century, American Journal of Public Health, 100(2): 357-363.

Society of Actuaries (SOA), 2010, Obesity and its Relation to Mortality and Morbidity Costs, SOA Research Projects series (Life Insurance), December.

SOA, 1983, The Bragg Smoker and Non-Smoker Mortality Tables and Health Insurance Report, The Actuary, October, 17(8): 5.

Sorlie, P., E. Rogot, R. Anderson, N.J. Johnson, and E. Backlund, 1992, Black-White Mortality Differences by Family Income, The Lancet, 340: 346-350.

Stewart, F., 2007, Policy Issues for Developing Annuities Markets, OECD Working Papers on Insurance and Private Pensions, No. 2, OECD Publishing.

The Investors Chronicle, 2008, How to Get the Best Annuity, December 31. www.investorschronicle.co.uk/InvestmentGuides/Pensions/article/20081231/be891c8ecd29-11dd-a7ab-00144f2af8e8/How-to-get-the-best-annuity.jsp, viewed on 10/31/2010.

Turra, C., and O.S. Mitchell, 2008, The Impact of Health Status and Out-of-Pocket Medical Expenditures on Annuity Valuation, in: J. Ameriks and O.S. Mitchell, eds., Recalibrating Retirement Spending and Saving, Oxford University Press, Oxford, UK, 227-250.

U.S. Supreme Court, 1988, Florida v. Long, 487 U.S. 223, June 22. http://supreme.justia.com/us/487/223/, viewed on 10/31/2010.

Wall Street Journal (WSJ.com), 2011, EU Insurance Ruling: More Pain for Women?, Commentary, March 1. http://blogs.wsj.com/source/2011/03/01/eu-insurance-ruling-morepain-for-women/, viewed on 3/30/2011. 
Figure 1: Survival function by Sex of 50 - 62 year olds first interviewed in 1992 in the Health and Retirement Study (Kaplan-Meier estimates)

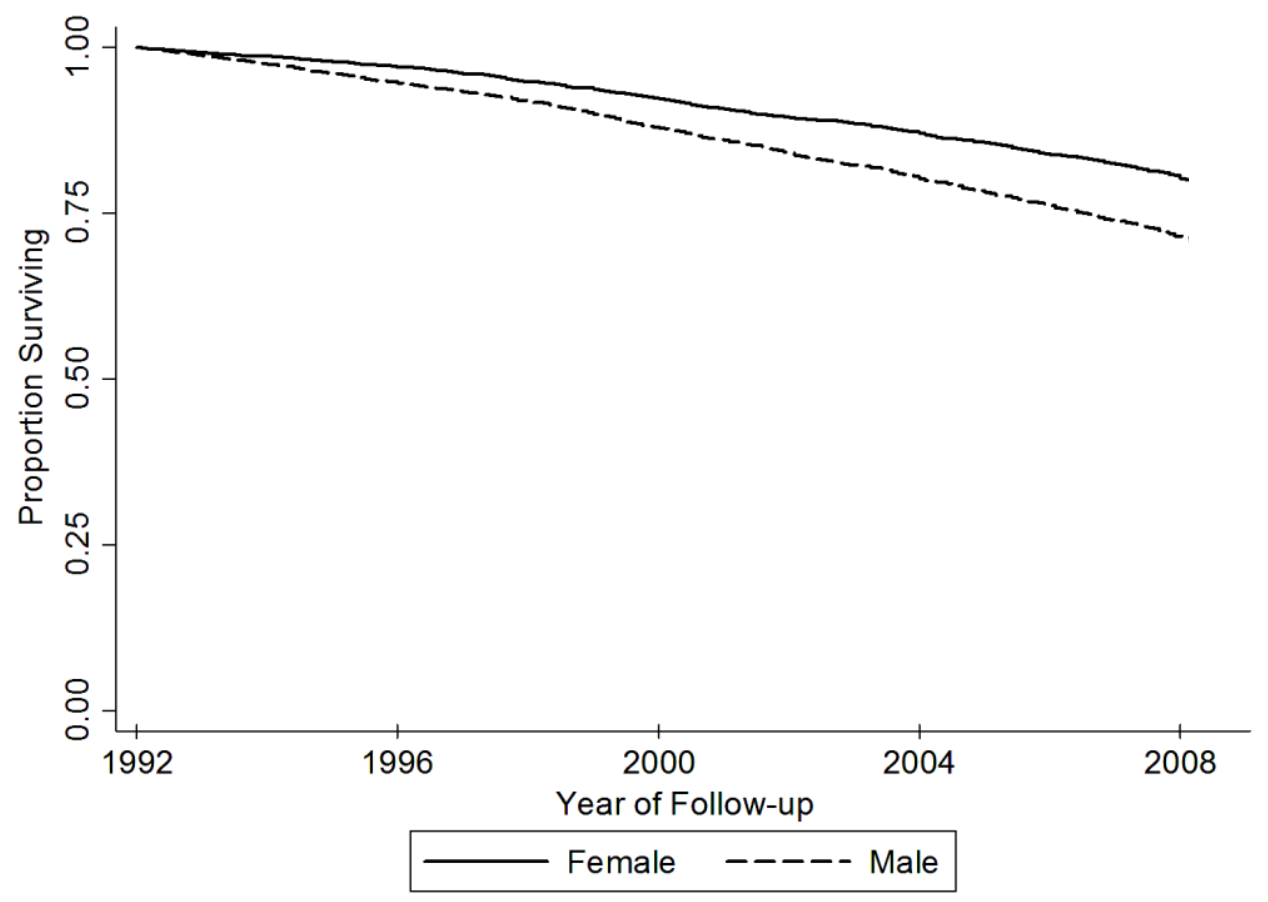

Note: The sample consists of 9,047 age-eligible respondents first interviewed in 1992 in the HRS (1992-2008). At the 2008 wave cut-off, $70 \%$ of males and $78 \%$ of females are still alive. The estimates presented are un-weighted. Incorporating base-year respondent-level weights to account for over-sampling of blacks, Hispanics, and Floridians in the HRS leads to very similar results. The slight variability at the ends of the survival functions is due to a reduced effective sample at the tail caused by prior failures and censoring.

Source: Author; see text. 


\section{Figure 2: Mortality Hazard Functions from Fitted Estimates of Gompertz PH Model 1}

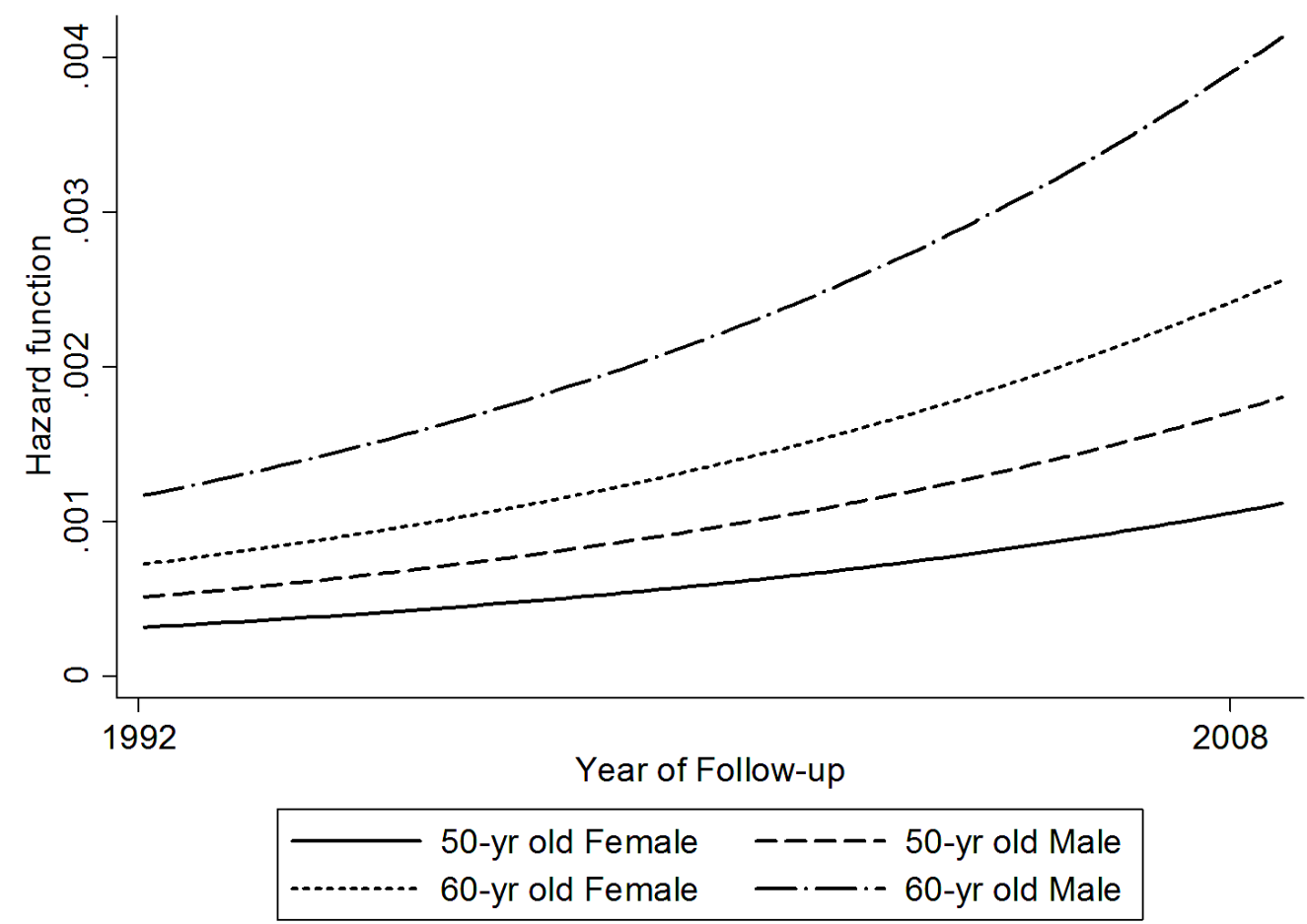

Note: The sample consists of 9,047 age-eligible respondents first interviewed in 1992 in the HRS (1992-2008). All proportional hazards regressions include base-year respondent-level weights to account for over-sampling of blacks, Hispanics, and Floridians in the HRS.

Source: Author; see text. 


\section{Figure 3: Density Function of the Age-at-Death random variable for Four Risk-groups}
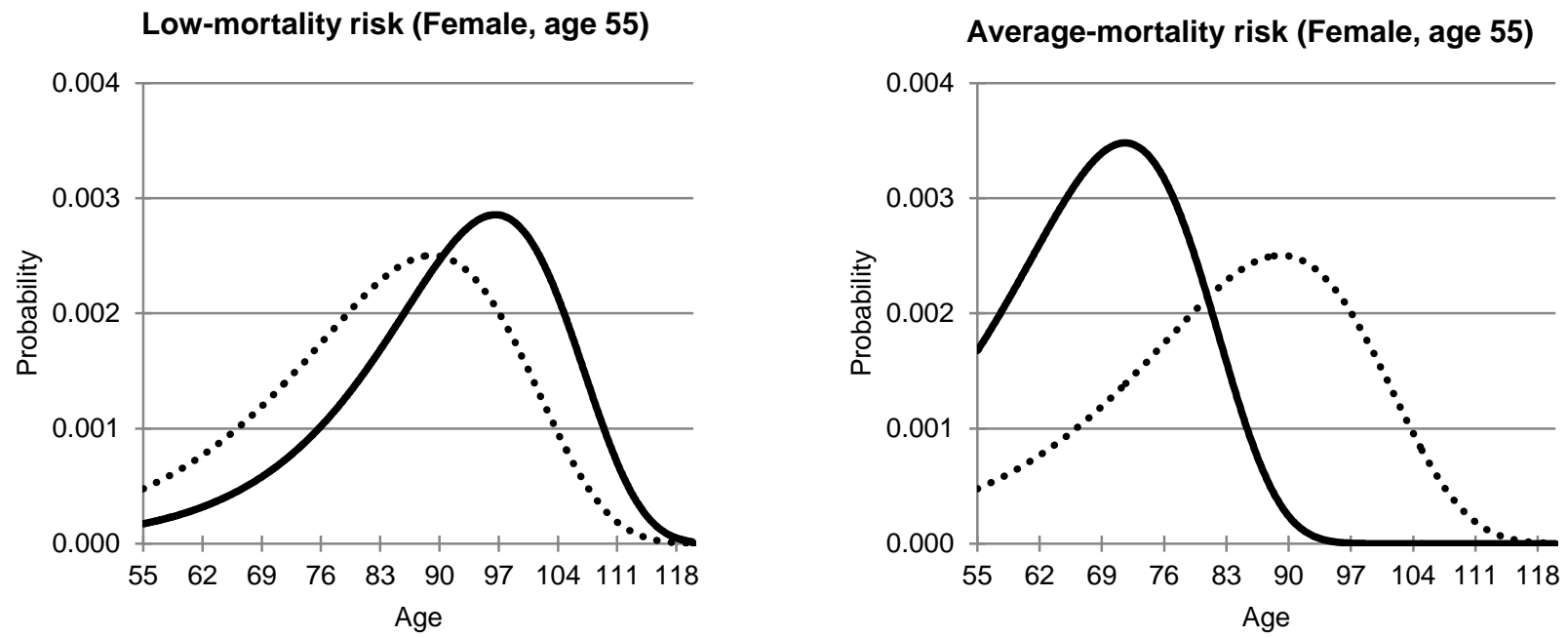

High-mortality risk (Female, age 55)

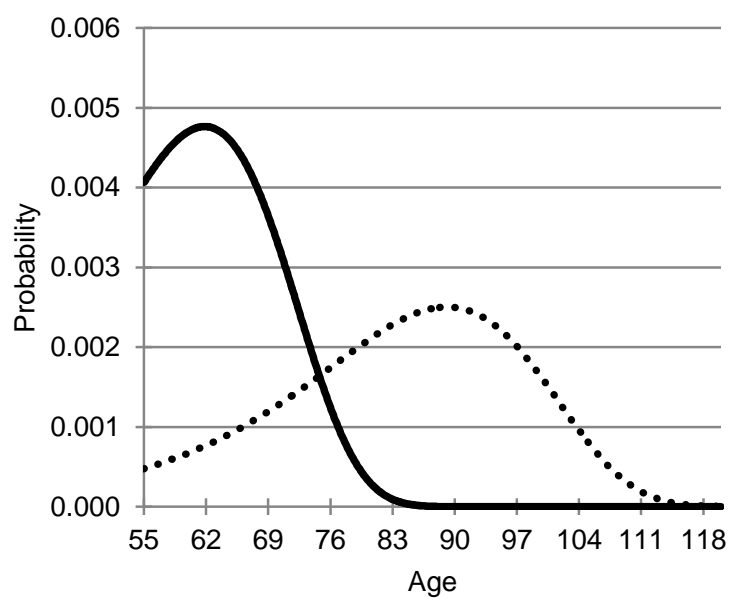

Very High-mortality risk (Male, age 58)

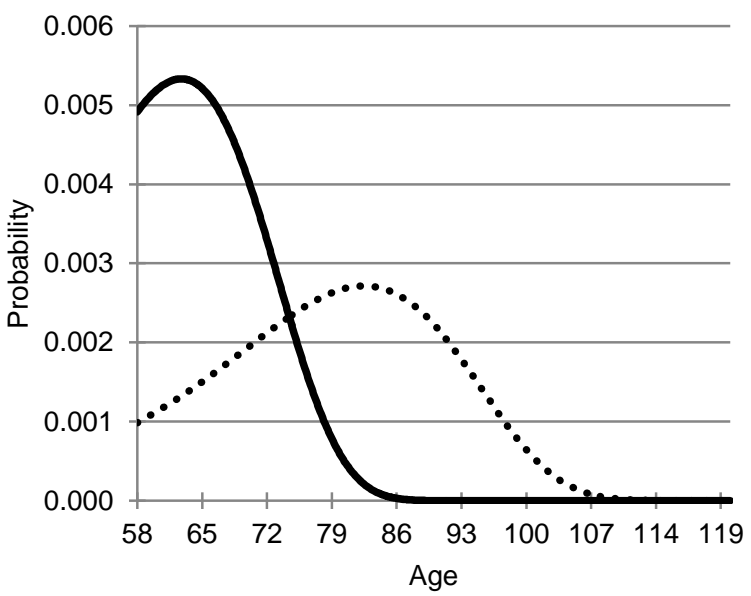

Legend: $\quad \cdots \cdots$ Age-sex Pricing Risk-class Pricing

Note: The graphs are based on fitted Gompertz proportional hazards regression estimates. For 'age-sex' pricing, only age and sex are specified in the regression. For 'risk-class' pricing, the following 12 controls are included: diabetes, lung disease, heart disease, sex, age, marital status, high blood, cancer, own schooling, BMI, psychiatric condition, and cognition. All regressions are weighted. The assumed terminal age is 120 . The density curves show the conditional probability of death at each age. The four risk-groups are characterized in the following manner:

- High-longevity risk: age 55 female, no disease history, overweight, married, high-school (HS) educated, aboveaverage cognition.

- Average risk: age 55 female, no disease history, normal weight but unmarried, not HS-educated, average cognition. (Note that this mortality profile is obtained by setting all 10 additional risk variables at their reference categories.)

- Low risk: age 55 female, ever-had cancer, underweight, unmarried, not HS-educated, below-average cognition.

- Very low risk: age 58 male, overweight, ever-had heart disease, high blood, and psychiatric illness, unmarried, not HS-educated, and of below-average cognition.

Source: Author; see text. 
Table 1: Hazard Ratios for Mortality in the HRS, 1992 - 2008, Gompertz Proportional Hazards Model $(N=9,047)$

\begin{tabular}{|c|c|c|c|c|}
\hline & (M1) & (M2) & (M3) & (M4) \\
\hline & HR $[95 \% \mathrm{CI}]$ & HR $[95 \% \mathrm{CI}]$ & HR $[95 \% \mathrm{CI}]$ & HR $[95 \% \mathrm{CI}]$ \\
\hline Age & $1.09[1.07,1.10]^{* * *}$ & $1.07[1.05,1.09] * * *$ & $1.07[1.05,1.08]^{* * *}$ & $1.08[1.06,1.09] * * *$ \\
\hline Male & $1.62[1.46,1.78]^{* * *}$ & $1.92[1.72,2.13] * * *$ & $1.83[1.64,2.05]^{* * *}$ & $1.69[1.51,1.89] * * *$ \\
\hline Nonwhite & & $1.18[1.05,1.33]^{* * *}$ & $1.14[1.00,1.30]^{* *}$ & $1.12[0.98,1.27]^{*}$ \\
\hline Years of schooling $\geq 12$ years & & $0.73[0.66,0.82]^{* * *}$ & $0.79[0.70,0.89]^{* * *}$ & $0.94[0.83,1.06]$ \\
\hline Married & & $0.69[0.62,0.77] * * *$ & $0.70[0.63,0.79]^{* * *}$ & $0.81[0.72,0.91] * * *$ \\
\hline \multicolumn{5}{|l|}{ BMI (ref=normal weight $)$ : } \\
\hline Underweight & & $2.93[2.18,3.93] * * *$ & $2.97[2.18,4.03]^{* * *}$ & $2.16[1.56,2.99] * * *$ \\
\hline Overweight & & $0.83[0.73,0.94] * * *$ & $0.83[0.73,0.94]^{* * *}$ & $0.87[0.77,0.98] * *$ \\
\hline Obese & & $0.85[0.74,0.98]^{* *}$ & $0.84[0.73,0.97]^{* *}$ & $0.89[0.77,1.02]^{*}$ \\
\hline \multicolumn{5}{|l|}{ Prior health history: } \\
\hline Ever-have Cancer $(=1)$ & & $1.99[1.62,2.44] * * *$ & $1.99[1.62,2.44]^{* * *}$ & $1.82[1.49,2.23]^{* * *}$ \\
\hline Diabetes & & $2.49[2.18,2.84] * * *$ & $2.49[2.19,2.85]^{* * *}$ & $2.18[1.90,2.50] * * *$ \\
\hline Heart disease / attack & & $1.63[1.42,1.87] * * *$ & $1.61[1.41,1.85]^{* * *}$ & $1.34[1.16,1.54] * * *$ \\
\hline High blood pressure & & $1.40[1.26,1.56] * * *$ & $1.37[1.23,1.53]^{* * *}$ & $1.30[1.16,1.45] * * *$ \\
\hline Chronic lung disease & & $2.28[1.93,2.69] * * *$ & $2.19[1.85,2.60] * * *$ & $1.62[1.37,1.91] * * *$ \\
\hline Major psychiatric condition & & $1.57[1.32,1.86]^{* * *}$ & $1.54[1.30,1.83]^{* * *}$ & $1.30[1.09,1.54] * * *$ \\
\hline Stroke & & $1.73[1.36,2.21] * * *$ & $1.71[1.34,2.19]^{* * *}$ & $1.47[1.16,1.87]^{* * *}$ \\
\hline Arthritis & & $1.06[0.95,1.18]$ & $1.05[0.94,1.17]$ & $0.93[0.83,1.04]$ \\
\hline \multicolumn{5}{|c|}{ Birth region (ref = Northeast region): } \\
\hline Midwest region & & & $0.90[0.77,1.06]$ & $0.90[0.77,1.06]$ \\
\hline South region & & & $0.96[0.83,1.12]$ & $0.90[0.77,1.04]$ \\
\hline West region & & & $0.74[0.58,0.93]^{* * *}$ & $0.75[0.59,0.94]^{* *}$ \\
\hline Not born in the U.S. & & & $0.63[0.50,0.80]^{* * *}$ & $0.64[0.51,0.81] * * *$ \\
\hline Cognition (memory score) & & & $0.97[0.96,0.99]^{* * *}$ & $0.98[0.97,0.99] * * *$ \\
\hline Father education $\geq 12$ years & & & $1.08[0.93,1.24]$ & $1.13[0.98,1.30]^{*}$ \\
\hline Mother education $\geq 12$ years & & & $0.93[0.81,1.07]$ & $0.94[0.82,1.08]$ \\
\hline Father's Longevity & & & $0.95[0.92,0.99]^{* * *}$ & $0.96[0.93,0.99]^{* *}$ \\
\hline Mother's Longevity & & & $1.00[0.96,1.04]$ & $1.00[0.97,1.04]$ \\
\hline \multicolumn{5}{|c|}{ Self-reported health (ref=excellent): } \\
\hline Very Good & & & & $1.27[1.05,1.54]^{* *}$ \\
\hline Good & & & & $1.68[1.39,2.02] * * *$ \\
\hline Fair & & & & $2.29[1.85,2.82] * * *$ \\
\hline Poor & & & & $3.02[2.38,3.81] * * *$ \\
\hline Currently smoke $(=1)$ & & & & $1.76[1.56,1.99] * * *$ \\
\hline Ever smoke $(=1)$ & & & & $1.41[1.23,1.62] * * *$ \\
\hline Ever drink $(=1)$ & & & & $0.94[0.84,1.05]$ \\
\hline $\operatorname{Gamma}(\gamma)$ & 0.0063 & 0.0076 & 0.0077 & 0.0081 \\
\hline \# observations & 58,467 & 58,467 & 58,467 & 58,467 \\
\hline$G^{2}$ & 190.78 & $1,287.06$ & $1,336.73$ & $1,622.97$ \\
\hline df & 2 & 16 & 30 & 37 \\
\hline Adjusted $R^{2}$ & $6.7 \%$ & $29.7 \%$ & $30.6 \%$ & $36.7 \%$ \\
\hline
\end{tabular}

Source: Author; see text.

Notes: $\mathrm{HR}=$ hazard ratios $(* \mathrm{p}<0.10, * * \mathrm{p}<0.05, * * * \mathrm{p}<0.01), \mathrm{CI}=95 \%$ confidence intervals in brackets.

The sample consists of 9,047 age-eligible HRS respondents first interviewed in 1992. Analyses are weighted by base-year respondent-level weights to account for over-sampling of blacks, Hispanics, and Floridians. M2 adds conventional, predetermined covariates (race, education, whether married, and weight), M3 adds less-conventional, predetermined risk factors (birth region, cognition scores, parental factors), and M4 adds conventional, endogenous variables (self-reported health, smoking, and drinking). $\gamma$ is the shape parameter of the baseline hazard. $G^{2}$ is the Wald chi-square statistic which compares the log pseudo-likelihood of the fitted model against a null model. A model with more parameters will always have a higher statistic; whether it fits significantly better than a model with fewer parameters is 
determined by calculating the p-value of the difference in $G^{2}$ between models, together with the associated degrees of freedom (df). The adjusted $R^{2}$ for survival models measures how much of the variation in outcome in a Gompertz proportional hazards model is accounted for through the prognostic index $(x \beta)$, adjusting the dimension of the model. Flags for missing, and imputed, values for these variables are included in the analysis: birth region, father's education, mother's education $(\mathrm{p}<.10)$, and parental longevity. 
Table 2: Benefit Flows to Annuitants (for age 65 annuity purchasers; $i=6 \%$ )

Subgroups of 65-year olds

Top: No high blood, Married, HS-educated, Females

Married, HS-educated, Females

HS-educated, Females

Females

65-year-olds

Males

Lowly-educated, Males

Not married, Lowly-educated, Males

Bottom: High blood, Not married, Lowly-educated, Males

\section{Expected Benefit Flows}

$\$ 152$

145

140

133

126

117

104

91

81

Notes: The benefit flows pertain to a standard, nominal, whole life, retail annuity that pays $\$ 1 /$ month to 65-year-old would-be annuity purchasers. Simulations are based on a nominal annual interest rate of $6 \%$ and a terminal age of 120. The risk-group of 'No high blood, Married, HS-educated, Females' is the longest-lived group analyzed in this Table and marked "Top". Correspondingly, 'High blood, Unmarried, Low-educated, Males' is the shortest-lived group and marked "Bottom".

Source: Author. 
Table 3: Annuity Premiums Charged under Different Pricing Schemes (for age 65 annuity purchasers; $i=6 \%$; zero-loads)

\begin{tabular}{|c|c|c|c|c|}
\hline $\begin{array}{c}\text { Different Pricing } \\
\text { Schemes }\end{array}$ & $\begin{array}{c}\text { \# of pricing } \\
\text { factors }\end{array}$ & \multicolumn{2}{|l|}{ Prices (\$) } & $\begin{array}{l}\text { \# of distinct } \\
\text { premiums }\end{array}$ \\
\hline Age-only & 1 & Single price: & $\$ 126$ & 1 \\
\hline Age, sex & 2 & $\begin{array}{l}\mathrm{F}: \\
\mathrm{M}:\end{array}$ & $\begin{array}{r}\$ 134 \\
117\end{array}$ & 2 \\
\hline Age, sex, education & 3 & $\begin{array}{l}\text { HS-educated F: } \\
\text { Less-educated F: } \\
\text { HS-educated M: } \\
\text { Less-educated M: }\end{array}$ & $\begin{array}{r}\$ 140 \\
122 \\
125 \\
104\end{array}$ & 4 \\
\hline $\begin{array}{l}\text { Age, sex, education, } \\
\text { marital status }\end{array}$ & 4 & $\begin{array}{l}\text { Married, HS-educated F: } \\
\text { Unmarried, HS-educated F: } \\
\text { Married, less-educated F: } \\
\text { Unmarried, less-educated F: } \\
\text { Married, HS-educated M: } \\
\text { Unmarried, HS-educated M: } \\
\text { Married, less-educated M: } \\
\text { Unmarried, less-educated M: }\end{array}$ & $\begin{array}{r}\$ 145 \\
129 \\
129 \\
111 \\
128 \\
110 \\
109 \\
91\end{array}$ & 8 \\
\hline $\begin{array}{l}: \\
:\end{array}$ & $\begin{array}{l}: \\
:\end{array}$ & $\begin{array}{l}: \\
:\end{array}$ & $\begin{array}{l}: \\
:\end{array}$ & $\begin{array}{l}: \\
:\end{array}$ \\
\hline $\begin{array}{l}\text { Age, sex, education, } \\
\text { marital status, high } \\
\text { blood, cognition }\end{array}$ & 6 & $\begin{array}{l}: \\
:\end{array}$ & $\$ 67-153$ & 32 \\
\hline $\begin{array}{l}: \\
:\end{array}$ & : & $\begin{array}{l}: \\
:\end{array}$ & $\begin{array}{l}: \\
:\end{array}$ & $\begin{array}{l}: \\
:\end{array}$ \\
\hline $\begin{array}{l}\text { All top } 12 \text { factors: } \\
\text { Age, sex, education, } \\
\text { marital status, high } \\
\text { blood, cognition, } \\
\text { diabetes, lung } \\
\text { disease, heart } \\
\text { disease, cancer, } \\
\text { BMI, psychiatric. }\end{array}$ & 12 & $\begin{array}{l}: \\
:\end{array}$ & $\$ 4-161$ & 4,096 \\
\hline
\end{tabular}

Notes: Only one of these pricing schemes is adopted by the insurer at any one time. Premiums are set by the insurer and offered to 65-year-old would-be annuity purchasers. Simulations are based on a single-life, nominal, standard retail annuity with fixed $\$ 1 /$ month payouts, a nominal interest rate of $6 \%$, and a terminal age of 120 . The distinct number of prices in each row is obtained by multiplying the number of categories that is associated with each additional pricing factor. For example, 'sex' is associated with only two categories (male/female) but 'BMI' is associated with four categories (underweight, normal weight, overweight, and obese). In addition, only a group of 65-year old annuitants is considered here. In other words, age is fixed. If age is allowed to vary, as it would in a random pool of annuitants, the number of distinct prices that will be larger than that indicated here. Source: Author; see text. 
Table 4: Money's Worth Ratios for Various Risk-groups under Different Pricing Schemes (age 65 annuity purchasers)

A: Money's Worth Ratios $(i=6 \%)$

\begin{tabular}{|c|c|c|c|c|}
\hline & \multicolumn{2}{|c|}{ Simpler Pricing } & \multicolumn{2}{|c|}{ More Detailed Pricing } \\
\hline & (S1) Age-only & $(\mathbf{S 2})+$ Sex & (S3) + Educ. & (S4) + Marital \\
\hline $\begin{array}{l}\text { Top: No high blood, Married, } \\
\text { High-school (HS)-educated, Females }\end{array}$ & 1.204 & 1.133 & 1.081 & 1.047 \\
\hline Married, HS-educated, Females & 1.150 & 1.082 & 1.032 & 1.000 \\
\hline HS-educated, Females & 1.114 & 1.048 & 1.000 & - \\
\hline Females & 1.062 & 1.000 & - & - \\
\hline 65-year-olds & 1.000 & - & - & - \\
\hline Males & 0.931 & 1.000 & - & - \\
\hline Low-educated, Males & 0.827 & 0.889 & 1.000 & - \\
\hline Unmarried, Low-educated, Males & 0.722 & 0.775 & 0.873 & 1.000 \\
\hline $\begin{array}{r}\text { Bottom: High blood, Unmarried, } \\
\text { Low-educated, Males }\end{array}$ & 0.645 & 0.693 & 0.780 & 0.893 \\
\hline Decline in MWR (for Top) & & $-6 \%$ & $-5 \%$ & $-3 \%$ \\
\hline Increase in MWR (for Bottom) & & $+7 \%$ & $+13 \%$ & $+15 \%$ \\
\hline
\end{tabular}

B: Money's Worth Ratios $(i=4 \%)$

\begin{tabular}{|c|c|c|c|c|}
\hline & \multicolumn{2}{|c|}{ Simpler Pricing } & \multicolumn{2}{|c|}{ More Detailed Pricing } \\
\hline & (S1) Age-only & (S2) + Sex & (S3) + Educ. & (S4) + Marital \\
\hline $\begin{array}{l}\text { Top: No high blood, Married, } \\
\text { High-school (HS)-educated, Females }\end{array}$ & 1.254 & 1.166 & 1.102 & 1.059 \\
\hline Married, HS-educated, Females & 1.184 & 1.101 & 1.040 & 1.000 \\
\hline HS-educated, Females & 1.138 & 1.059 & 1.000 & - \\
\hline Females & 1.075 & 1.000 & - & - \\
\hline 65-year-olds & 1.000 & - & - & - \\
\hline Males & 0.918 & 1.000 & - & - \\
\hline Low-educated, Males & 0.801 & 0.872 & 1.000 & - \\
\hline Unmarried, Low-educated, Males & 0.686 & 0.747 & 0.857 & 1.000 \\
\hline $\begin{array}{r}\text { Bottom: High blood, Unmarried, } \\
\text { Low-educated, Males }\end{array}$ & 0.605 & 0.659 & 0.756 & 0.882 \\
\hline Decline in MWR (for Top) & & $-7 \%$ & $-6 \%$ & $-4 \%$ \\
\hline Increase in MWR (for Bottom) & & $+9 \%$ & $+15 \%$ & $+17 \%$ \\
\hline
\end{tabular}

Notes: These calculations are the MWR values available to 65-year-old would-be annuity purchasers. The dashes indicated cases where the premium for that risk-group cannot be defined under the prevailing pricing scheme. Simulations are based on a single-life, nominal annuity with fixed $\$ 1 /$ month payouts, a nominal interest rate of $4 \%$ or $6 \%$, and a terminal age of 120 . S1 denotes a pricing scheme using 1 risk-class (age-only); $\mathrm{S} 2$ denotes a scheme using 2 risk-classes (age and sex), and so on. For example, the S4 scheme uses four pricing factors: age, sex, education, and marital status. The risk-group of 'No high blood, Married, HS-educated, Females' is the longest-lived group analyzed in this Table and marked "Top". Correspondingly, 'High blood, Unmarried, Low-educated, Males' is the shortest-lived group and marked "Bottom". Moving from left to right, the relative change in MWR for both of these groups is shown at the end of the Table.

Source: Author; see text. 
Table 5: Annual Annuity Income from \$100,000 Policy under Different Pricing Schemes (for age 65 annuity purchasers; $r=\pi=3 \%$; zero-loads)

\begin{tabular}{rcc|cc}
\hline & \multicolumn{2}{c|}{ Simpler Pricing } & \multicolumn{2}{c}{ More Detailed Pricing } \\
\cline { 2 - 5 } & $\begin{array}{c}\text { S1 } \\
\text { Age-only }\end{array}$ & $\begin{array}{c}\text { S2 } \\
+ \text { Sex }\end{array}$ & $\begin{array}{c}\text { S3 } \\
+ \text { Educ. }\end{array}$ & $\begin{array}{c}\text { S4 } \\
+ \text { Marital }\end{array}$ \\
\hline $\begin{array}{r}\text { Top: No high blood, Married, } \\
\text { High-school (HS)-educated, Females }\end{array}$ & $\$ 10,109$ & $\$ 9,492$ & $\$ 9,036$ & $\$ 8,742$ \\
Married, HS-educated, Females & 10,109 & 9,492 & 9,036 & 8,742 \\
HS-educated, Females & 10,109 & 9,492 & 9,036 & - \\
Females & 10,109 & 9,492 & - & - \\
65-year-olds & 10,109 & - & - & - \\
Males & 10,109 & 10,898 & - & - \\
Low-educated, Males & 10,109 & 10,898 & 12,344 & 14,269 \\
Bottom: High blood, Unmarried, & 10,109 & 10,898 & 12,344 & 14,269 \\
Low-educated, Males & 10,109 & 10,898 & 12,344 & \\
\hline Unmarried, Low-educated, Males & & & & - \\
\hline
\end{tabular}

Notes: These calculations are based on a single-life, nominal, standard retail annuity that charges a lump-sum premium of $\$ 100,000$ in exchange for fixed annual payouts. Additional parameters include a real interest rate of $3 \%$, an inflation rate of $3 \%$, an annuitization age of 65 , and a terminal age of 120. S1 denotes a pricing scheme using 1 risk-class (age-only); S2 denotes a scheme using 2 risk-classes (age and sex), and so on. For example, the S4 scheme uses four pricing factors: age, sex, education, and marital status. The dashes indicated cases where the annuity payout for that risk-group cannot be defined under the prevailing pricing scheme; for example, it is necessary to determine the educational status of the annuitant under Scheme S3 since low-educated annuitants will receive higher annuity income. The risk-group of 'No high blood, Married, HS-educated, Females' is the longest-lived group analyzed in this Table and marked "Top". Correspondingly, 'High blood, Unmarried, Low-educated, Males' is the shortest-lived group and marked "Bottom".

Source: Author; see text. 
Table 6: Annuity Equivalent Wealth for Various Risk-groups under Different Pricing Schemes (age 65 annuity purchasers; $r=\pi=3 \%$; zero-loads)

\section{A: CRRA utility with $\gamma=3$}

\begin{tabular}{rcc|cc}
\hline & \multicolumn{2}{c|}{ Simpler Pricing } & \multicolumn{2}{c}{ More Detailed Pricing } \\
\cline { 2 - 5 } & (S1) Age-only & $\mathbf{( S 2 ) + \text { Sex }}$ & $\mathbf{( S 3 ) + \text { Educ. }}$ & $\mathbf{( S 4 )}+$ Marital \\
\hline Top: No high blood, Married, & 1.592 & 1.495 & 1.421 & 1.374 \\
High-school (HS)-educated, Females & & 1.488 & 1.415 & 1.368 \\
Married, HS-educated, Females & 1.583 & 1.482 & 1.411 & - \\
HS-educated, Females & 1.577 & 1.474 & - & - \\
Females & 1.568 & - & - & - \\
65-year-olds & 1.552 & 1.644 & - & - \\
Males & 1.527 & 1.586 & 1.791 & 1.972 \\
Low-educated, Males & 1.471 & 1.512 & 1.709 & 1.882 \\
Unmarried, Low-educated, Males & 1.406 & 1.445 & 1.633 & $\mathbf{- 3 \%}$ \\
Bottom: High blood, Unmarried, & 1.342 & & $\mathbf{- 5 \%}$ & $\mathbf{+ 1 5 \%}$ \\
Low-educated, Males & & $\mathbf{+ 8 \%}$ & $\mathbf{+ 1 3 \%}$ &
\end{tabular}

B: CRRA utility with $\gamma=1$

\begin{tabular}{|c|c|c|c|c|}
\hline & \multicolumn{2}{|c|}{ Simpler Pricing } & \multicolumn{2}{|c|}{ More Detailed Pricing } \\
\hline & (S1) Age-only & $(\mathrm{S} 2)+\mathrm{Sex}$ & (S3) + Educ. & (S4) + Marital \\
\hline $\begin{array}{l}\text { Top: No high blood, Married, } \\
\text { High-school (HS)-educated, Females }\end{array}$ & 1.535 & 1.441 & 1.372 & 1.328 \\
\hline Married, HS-educated, Females & 1.509 & 1.419 & 1.351 & 1.307 \\
\hline HS-educated, Females & 1.492 & 1.402 & 1.336 & - \\
\hline Females & 1.466 & 1.377 & - & - \\
\hline 65-year-olds & 1.429 & - & - & - \\
\hline Males & 1.376 & 1.483 & - & - \\
\hline Low-educated, Males & 1.289 & 1.388 & 1.571 & - \\
\hline Unmarried, Low-educated, Males & 1.192 & 1.279 & 1.447 & 1.671 \\
\hline $\begin{array}{r}\text { Bottom: High blood, Unmarried, } \\
\text { Low-educated, Males }\end{array}$ & 1.127 & 1.198 & 1.346 & 1.554 \\
\hline Decline in AEW (for Top) & & $-6 \%$ & $-5 \%$ & $-3 \%$ \\
\hline Increase in AEW (for Bottom) & & $6 \%$ & $12 \%$ & $15 \%$ \\
\hline
\end{tabular}

Notes: These calculations are based on a single-life, nominal annuity that charges a lump-sum premium of $\$ 100,000$ in exchange for fixed annual payouts (as illustrated in Table 5). Additional parameters include a real interest rate of 3\%, an inflation rate of $3 \%$, an annuitization age of 65 , and a terminal age of 120. S1 denotes a pricing scheme using 1 risk-class (age-only); S2 denotes a scheme using 2 risk-classes (age and sex), and so on. For example, scheme S4 uses four pricing factors: age, sex, education, and marital status. The dashes in the Table represent cases where annuity pricing cannot be defined for that risk-group, thus AEW is not computed for that group.

Source: Author; see text. 


\section{Appendix Table 1: Descriptive Statistics}

This Table provides basic descriptive statistics of the sample of 9,047 respondents in the baseline HRS cohort. Age distribution is pretty even across the range of 51-61; average age is 56. About $79 \%$ of the respondents are white, $95 \%$ have a religion, and $90 \%$ are born in the US. Average education is about 12.1 years of schooling. About a third of the individuals are normal weight, $1.3 \%$ is underweight, and the rest are overweight or obese. In terms of parental factors, father's years of schooling is slightly lower than that of mother's, and more respondents' mothers are alive at baseline than fathers.

\begin{tabular}{|c|c|}
\hline Variable & Mean \\
\hline \multicolumn{2}{|l|}{ Individual demographic characteristics } \\
\hline Male & $45.4 \%$ \\
\hline Average age at interview & $56.0(3.18)$ \\
\hline Race: nonwhite & $21.2 \%$ \\
\hline Married & $72.7 \%$ \\
\hline Born in the US & $90.3 \%$ \\
\hline Has religion & $95.3 \%$ \\
\hline \multicolumn{2}{|l|}{ Place of birth (by region): } \\
\hline 1. Northeast & $17.6 \%$ \\
\hline 2. Midwest & $25.3 \%$ \\
\hline 3. South & $38.7 \%$ \\
\hline 4. West & $7.9 \%$ \\
\hline 5. Not born in the U.S. & $10.5 \%$ \\
\hline \multicolumn{2}{|l|}{ Socioeconomic factors } \\
\hline Own years of schooling & $12.1(3.20)$ \\
\hline Father's years of schooling & $8.8(3.81)$ \\
\hline Mother's years of schooling & $9.1(3.52)$ \\
\hline \multicolumn{2}{|l|}{ Parental longevity } \\
\hline Father alive & $16.4 \%$ \\
\hline Mother alive & $42.2 \%$ \\
\hline Father's age at death (if deceased) & $68.0(13.85)$ \\
\hline Mother's age at death (if deceased) & $68.5(14.93)$ \\
\hline Father's current age (if alive) & $80.9(5.62)$ \\
\hline Mother's current age (if alive) & $79.3(5.85)$ \\
\hline \multicolumn{2}{|l|}{ Health \& Cognition } \\
\hline \multicolumn{2}{|l|}{ BMI: } \\
\hline Underweight $(\mathrm{BMI}<18.5)$ & $1.3 \%$ \\
\hline Normal weight $(18.5 \leq \mathrm{BMI}<25)$ & $33.6 \%$ \\
\hline Overweight $(25 \leq \mathrm{BMI}<30)$ & $40.8 \%$ \\
\hline Obese $(30 \leq \mathrm{BMI})$ & $24.3 \%$ \\
\hline
\end{tabular}




\begin{tabular}{|c|c|c|}
\hline Variable & & Mean \\
\hline & Ever-have Cancer & $4.8 \%$ \\
\hline & Ever-have Diabetes & $9.6 \%$ \\
\hline & Ever-have Heart condition & $10.6 \%$ \\
\hline & Ever-have High blood pressure & $34.7 \%$ \\
\hline & Ever-have chronic lung disease & $5.3 \%$ \\
\hline & Ever-have major psychiatric condition & $7.1 \%$ \\
\hline & Ever-have Stroke & $2.4 \%$ \\
\hline & Ever-have Arthritis & $34.5 \%$ \\
\hline & Cognition: Memory score only (scale $0-40$ ) & $12.8(5.24)$ \\
\hline$N$ & & 9,047 \\
\hline
\end{tabular}

Notes: Percentages are shown for dichotomous variables, and means with standard deviations in parentheses are shown for continuous variables and some categorical variables (e.g. years of schooling). Statistics shown here are solely for baseline 1992 variables. The baseline cognition measure features only the memory score (based on word recall items) as the rest of the cognition test questions were not asked until wave 3. Missing values for these variables are flagged: parental education, parental longevity, birth region, BMI, and cognition scores. The birth regions are organized as follows: the Northeast Region comprises New England and Middle Atlantic divisions; the Midwest Region comprises East North and West North divisions; the South region comprises South Atlantic, East South, and West South divisions; the West region comprises Mountain and Pacific divisions.

Source: Author. 
Appendix Table 2: Comparing Hazard Ratios for Mortality in the HRS by Age Groups (1992 - 2008, Gompertz proportional hazards model, $N=9,047)$

\begin{tabular}{|c|c|c|c|}
\hline & \multirow{2}{*}{\begin{tabular}{l}
\multicolumn{1}{c}{$(\mathrm{M3})$} \\
All Ages \\
HR $[95 \% \mathrm{CI}]$
\end{tabular}} & \multicolumn{2}{|c|}{ (M3) By Age Group } \\
\hline & & $\begin{array}{l}\text { Age 50-57 } \\
\text { HR }[95 \% \mathrm{CI}]\end{array}$ & $\begin{array}{l}\text { Age 58-62 } \\
\text { HR [95\% CI] }\end{array}$ \\
\hline Age & $1.07[1.05,1.08]^{* * *}$ & $1.05[1.02,1.08]^{* * *}$ & $1.04[0.97,1.12]$ \\
\hline Male & $1.83[1.64,2.05]^{* * *}$ & $1.78[1.54,2.05]^{* * *}$ & $1.89[1.59,2.25]^{* * *}$ \\
\hline Nonwhite & $1.14[1.00,1.30]^{* *}$ & $1.13[0.95,1.34]$ & $1.12[0.91,1.37]$ \\
\hline Years of schooling $\geq 12$ years & $0.79[0.70,0.89]^{* * *}$ & $0.81[0.68,0.95]^{* * *}$ & $0.77[0.64,0.93]^{* * *}$ \\
\hline Married & $0.70[0.63,0.79]^{* * *}$ & $0.71[0.61,0.82]^{* * *}$ & $0.69[0.58,0.83]^{* * *}$ \\
\hline \multicolumn{4}{|l|}{ BMI (ref=normal weight): } \\
\hline Underweight & $2.97[2.18,4.03]^{* * *}$ & $3.15[2.16,4.60]^{* * *}$ & $2.59[1.55,4.33]^{* * *}$ \\
\hline Overweight & $0.83[0.73,0.94]^{* * *}$ & $0.82[0.69,0.97]^{* *}$ & $0.84[0.70,1.02]^{*}$ \\
\hline Obese & $0.84[0.73,0.97]^{* *}$ & $0.87[0.72,1.04]$ & $0.80[0.64,1.01]^{*}$ \\
\hline \multicolumn{4}{|l|}{ Prior health history: } \\
\hline Ever-have Cancer (=1) & $1.99[1.62,2.44]^{* * *}$ & $2.25[1.72,2.93] * * *$ & $1.72[1.26,2.36]^{* * *}$ \\
\hline Diabetes & $2.49[2.19,2.85]^{* * *}$ & $2.61[2.18,3.13]^{* * *}$ & $2.38[1.95,2.90]^{* * *}$ \\
\hline Heart disease / attack & $1.61[1.41,1.85]^{* * *}$ & $1.72[1.43,2.07] * * *$ & $1.48[1.20,1.83]^{* * *}$ \\
\hline High blood pressure & $1.37[1.23,1.53]^{* * *}$ & $1.40[1.21,1.62]^{* * *}$ & $1.33[1.13,1.58]^{* * *}$ \\
\hline Chronic lung disease & $2.19[1.85,2.60] * * *$ & $2.01[1.60,2.53] * * *$ & $2.60[2.03,3.33]^{* * *}$ \\
\hline Major psychiatric condition & $1.54[1.30,1.83]^{* * *}$ & $1.56[1.25,1.95]^{* * *}$ & $1.44[1.08,1.91]^{* *}$ \\
\hline Stroke & $1.71[1.34,2.19] * * *$ & $1.81[1.27,2.57] * * *$ & $1.61[1.16,2.22] * * *$ \\
\hline Arthritis & $1.05[0.94,1.17]$ & $1.00[0.87,1.16]$ & $1.11[0.94,1.31]$ \\
\hline \multicolumn{4}{|l|}{ Birth region (ref $=$ Northeast): } \\
\hline Midwest region & $0.90[0.77,1.06]$ & $0.84[0.68,1.03]^{*}$ & $1.00[0.78,1.27]$ \\
\hline South region & $0.96[0.83,1.12]$ & $0.91[0.74,1.10]$ & $1.06[0.84,1.33]$ \\
\hline West region & $0.74[0.58,0.93]^{* * *}$ & $0.66[0.49,0.91] * *$ & $0.83[0.59,1.18]$ \\
\hline Not born in the U.S. & $0.63[0.50,0.80]^{* * *}$ & $0.64[0.47,0.86] * * *$ & $0.63[0.44,0.89]^{* * *}$ \\
\hline Cognition (memory score) & $0.97[0.96,0.99]^{* * *}$ & $0.98[0.96,0.99] * * *$ & $0.97[0.95,0.99] * * *$ \\
\hline Father education $\geq 12$ years & $1.08[0.93,1.24]$ & $0.97[0.81,1.16]$ & $1.26[1.00,1.59]^{* *}$ \\
\hline Mother education $\geq 12$ years & $0.93[0.81,1.07]$ & $0.91[0.76,1.08]$ & $0.96[0.77,1.19]$ \\
\hline Father's Longevity & $0.95[0.92,0.99]^{* * *}$ & $0.93[0.89,0.98]^{* * *}$ & $0.99[0.94,1.05]$ \\
\hline Mother's Longevity & $1.00[0.96,1.04]$ & $0.99[0.94,1.04]$ & $1.01[0.96,1.07]$ \\
\hline $\operatorname{Gamma}(\gamma)$ & 0.0077 & 0.0077 & 0.0078 \\
\hline \# observations & 58,467 & 40,525 & 17,942 \\
\hline$G^{2}$ & $1,336.73$ & 771.327 & 555.9522 \\
\hline df & 30 & 30 & 30 \\
\hline
\end{tabular}

Notes: $\mathrm{HR}=$ hazard ratios $(* \mathrm{p}<0.10, * * \mathrm{p}<0.05, * * * \mathrm{p}<0.01), \mathrm{CI}=95 \%$ confidence intervals in brackets.

The sample consists of 9,047 age-eligible HRS respondents first interviewed in 1992. Analyses are weighted by base-year respondent-level weights to account for over-sampling of blacks, Hispanics, and Floridians. $\gamma$ is the shape parameter of the baseline hazard. $G^{2}$ is the Wald chi-square statistic which compares the log pseudo-likelihood of the fitted model against a null model. Flags for missing, and imputed, values for these variables are included in the analysis: birth region, father's education, mother's education $(\mathrm{p}<.10)$, and parental longevity.

Source: Author; see text. 